\title{
Apoliporotein L3 interferes with endothelial tube formation via regulation of ERK1/2, FAK and Akt signaling pathway
}

\author{
Alia Khalil ${ }^{\mathrm{a}, \mathrm{b}}$, Philippe Poelvoorde ${ }^{\mathrm{c}}$, Mohammad Fayyad-Kazan ${ }^{\mathrm{c}}$, Alexandre Rousseau $^{\mathrm{a}}$, \\ Vincent Nuyens $^{\mathrm{a}}$, Sophie Uzureau ${ }^{\mathrm{d}}$, Patrick Biston ${ }^{\mathrm{a}}$, Yolla EL-Makhour ${ }^{\mathrm{b}}$, Bassam Badran ${ }^{\mathrm{b}}$, \\ Pierre Van Antwerpen ${ }^{\mathrm{e}}$, Karim Zouaoui Boudjeltiaa ${ }^{\mathrm{a}, 1}$, Luc Vanhamme ${ }^{\mathrm{c}, *, 1}$ \\ ${ }^{a}$ Laboratory of Experimental Medicine (ULB 222 Unit), CHU de Charleroi, A. Vésale Hospital, Université Libre de Bruxelles, Montigny-le-Tilleul, Belgium \\ ${ }^{\mathrm{b}}$ Laboratory of Cancer Biology and Molecular Immunology, Lebanese University, Faculty of Sciences, Hadath-Beirut, Lebanon \\ ${ }^{\mathrm{c}}$ Laboratory of Molecular Biology of Inflammation, IBMM, Faculty of Sciences, Université Libre de Bruxelles, Gosselies, Belgium \\ ${ }^{\mathrm{d}}$ Laboratory of Molecular Parasitology, IBMM, Faculty of Sciences, Université Libre de Bruxelles, Gosselies, Belgium \\ ${ }^{\mathrm{e}}$ Laboratory of Pharmaceutical Chemistry and Analytical Platform of the Faculty of Pharmacy, Faculty of Pharmacy, Université Libre de Bruxelles, Brussels, Belgium
}

\section{H I G H L I G H T S}

- Members of the Apolipoprotein L family (APOL) are induced in endothelial cells by a variety of inflammatory stimuli.

- APOL3 is the only APOL commonly induced by atherogenic stimuli such as thrombin, MPO or oxidized LDL.

- APOL3 is also induced by angiogenic stimuli such as VEGF and FGF.

- APOL3 invalidation decreases tubulogenesis and endothelial wound repair. It increases endothelial permeability.

- APOL3 invalidation correlates with inhibition of pro-angiogenic pathways and reduces expression of pro-angiogenic genes.

A R T I C L E I N F O

\section{Keywords:}

Apolipoprotein L

Angiogenesis

Endothelial cell

Endothelial dysfunction

Inflammation

\begin{abstract}
A B S T R A C T
Background and aims: Endothelial cells are main actors in vascular homeostasis as they regulate vascular pressure and permeability as well as hemostasis and inflammation. Disturbed stimuli delivered to and by endothelial cells correlate with the so-called endothelial dysfunction and disrupt this homeostasis. As constituents of the inner layer of blood vessels, endothelial cells are also involved in angiogenesis. Apolipoprotein Ls (APOL) comprise a family of newly discovered apolipoproteins with yet poorly understood function, and are suggested to be involved in inflammatory processes and cell death mechanisms. Here we investigate the role of APOLs in endothelial cells stimulated with factors known to be involved in atherogenesis and their possible contribution to endothelial dysfunction with an emphasis on inflammation driven-angiogenesis in vitro.

Methods: Using the CRISPR/Cas9 technique, we analyzed the effect of APOL3 gene knock out in HMEC-1 endothelial cells on cell migration, tubulogenesis, endothelial permeability, intracellular signal transduction as assessed by kinase phosphorylation, and angiogenesis gene expression (measured by qRT-PCR).

Results: Our results indicate that among the family, APOL3 was the only member induced by myeloperoxidase, oxidized LDL, VEGF and FGF treatments. APOL3 invalidation increased endothelial permeability, reduced wound repair and tubule formation in vitro, the latter only in MPO and VEGF-induced conditions. Accordingly, some pro-angiogenic signaling pathways (ERK1/2 and FAK but not Akt) and some pro-angiogenic genes were partially inhibited in APOL3 knock out cells.
\end{abstract}

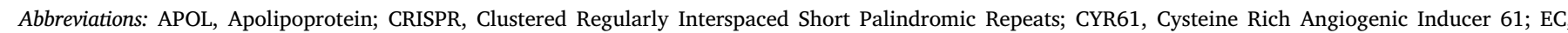

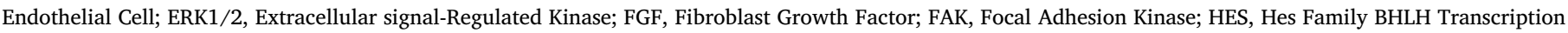

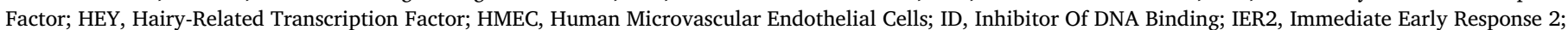

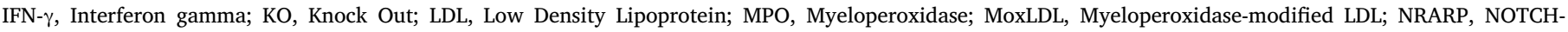

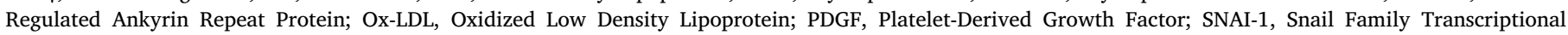
Repressor 1; VEGF, Vascular Endothelial Growth Factor; TNF- $\alpha$, Tumor Necrosis Factor alpha

* Corresponding author. Laboratoire de biologie moléculaire de l'inflammation, IBMM-ULB, 12, rue des Professeurs Jeener et Brachet, 6041, Gosselies, Belgium.

E-mail address: luc.vanhamme@ulb.ac.be (L. Vanhamme).

${ }^{1}$ These authors contributed equally to this work.
} 
Conclusions: These findings suggest the involvement of APOL3 in angiogenesis in vitro and as a modulator of MAPK and FAK signaling in endothelial cells.

\section{Introduction}

The endothelium is a single cell layer that forms the innermost stratum of blood vessels. As part of the blood vessel wall, its most evident function is to constitute an active semi permeable barrier involved in both partition and exchange of fluids, ions, biological molecules and cells between blood and other tissues. Endothelial cells are therefore actors in the process of angiogenesis, the creation of new blood vessels from preexisting ones. Endothelial cells also play a regulatory role in other functions including hemostasis, vascular tone or interactions with blood cells. These controls involve the expression of molecules implicated in the fine tuning of the balance between coagulation and fibrinolysis, vasoconstriction and vasodilation, or leukocyte repelling and recruitment respectively. Endothelial dysfunction is the perturbation of this balance and is involved in the development of various pathologies such as tumor development, metastasis and cardiovascular diseases [1].

Twenty years ago, apolipoprotein L1 (APOL1) was uncovered as a new component of human serum [2]. Its levels correlated with triglyceride levels $[3,4]$. It conferred to the human species the ability to resist infection by most African trypanosome species [5]. APOL1 belongs to a family of several dozens of diverging members (all mammalian species included, containing for example 6, 14 and 8 members in humans, mice and rats respectively). APOL1 is only present in humans and some African great apes. It is the only family member to be secreted in the serum, where it associates with the densest HDL fraction, HDL3 [6]. Twenty years later, the characterization of APOL1 has progressed in terms of trypanolysis mechanism and pathological effects since mutant alleles that confer resistance to some African trypanosomes are known to be associated to a lethal kidney disease [7]. However its physiological function remains enigmatic. Furthermore, the function of the other APOL family members remains largely unknown. A hint is provided by resemblances between APOLs and proteins of the apoptotic BCL-2 family: a multihelical ionic pore-forming domain and a BCL-2 homology 3 (BH3) domain suggest a role in programmed cell death [8]. Accordingly, ectopic expression of APOL1 and APOL6 in cancer cells triggered a cell death process exhibiting properties shared with autophagy and apoptosis respectively $[9,10]$. APOL2 has an anti-apoptotic effect on broncho-alveolar cells treated with IFN- $\gamma$ [11]. APOLs are induced under inflammatory conditions (IFN- $\gamma$, TNF- $\alpha$ ) in different cell types both in humans (APOL1, APOL3) and mice (APOL7, APOL11) [12-14].

Here we investigate the role of APOLs in endothelial cells stimulated with factors known to be involved in atherogenesis. We report that APOL3 is involved in endothelial function. In particular it plays a role in angiogenic activities of endothelial cells such as capillary network formation, cell migration, angiogenic signal transduction pathways and angiogenic gene expression.

\section{Materials and methods}

\subsection{Cell culture}

Human microvascular endothelial cells (HMEC-1) obtained from the Center for Disease Control (Atlanta, Georgia), were cultured in MCDB131 media (Gibco) supplemented with $10 \%$ fetal bovine serum (FBS), Lglutamine $(2 \mathrm{mmol} / \mathrm{L})$, human epidermal growth factor $(10 \mathrm{ng} / \mathrm{ml})$, penicillin/streptomycin $(50 \mu \mathrm{g} / \mathrm{ml})$ and hydrocortisone $(1 \mu \mathrm{g} / \mathrm{ml})$ in a $\mathrm{CO}_{2} / \mathrm{O}_{2}$ incubator at $37^{\circ} \mathrm{C}$.

\subsection{APOL3 knockout via CRISPR/Cas9}

Cells were transfected with the plasmid U6-gRNA/CMV-CAS9-GFP expressing a guide RNA targeting the APOL3 gene (Fig. S2) (Sigma Aldrich) using lipofectamine 2000 Transfection Reagent (thermofisher) according to the manufacturer's protocol. Briefly, the day before transfection, HMEC-1 were seeded at 50\% confluence in 6 well plates and cultured in growth medium without antibiotics for $24 \mathrm{~h}$. The next day, cells were washed in MCDB131 medium and transfection was performed in serum-free medium without antibiotics. Transfected GFP positive cells were sorted using a flow cytometer, seeded at one cell/ well in 96 well plates and allowed to grow. Genomic DNA was extracted from the growing clones. The genomic region targeted by the CRISPR/ Cas 9 procedure was amplified by PCR and cloned. After sequencing of the crude PCR product, 15 to 20 individually cloned PCR products were sequenced.

\subsection{Recombinant $M P O$ preparation}

Recombinant MPO was prepared as described previously [15]. Briefly, the pNIV2703 plasmid that codes for prepromyeloperoxidase was constructed. It contains an MPO ORF coding for a sequence from amino acid 11 in the putative signal sequence to amino acid 696 . The pNIV2703 expression vector was transfected into $\mathrm{CHO}$ cells by electroporation. Cell supernatants were recovered to assay the production level and the enzymatic activity of secreted molecules. Each batch solution was characterized for its activity (in $\mathrm{U} / \mathrm{ml}$ ), protein concentration (in $\mathrm{mg} / \mathrm{ml}$ ) and specific activity. Peroxidase activity was determined using $o$-dianiside as a substrate. Each batch was checked for endotoxin using the Lonza Endotoxin Detection Kit QCL-1000 (Catalog Number: 50-647U).

\subsection{LDL isolation and oxidation}

Native LDLs (NatLDLs) were obtained by sequential density gradient ultracentrifugation from plasma of healthy blood donors. The concentration of NatLDL in PBS was adjusted to $1 \mathrm{mg} / \mathrm{ml}$ before incubation with $10 \mu \mathrm{M}$ copper sulfate for $24 \mathrm{~h}$ at $37^{\circ} \mathrm{C}$. The oxidation was stopped by the addition of $25 \mu \mathrm{M}$ butylated hydroxytoluene and incubation on ice for $1 \mathrm{~h}$. MoxLDL were generated by mixing $8 \mu \mathrm{l}$ of $\mathrm{HCl} \mathrm{1M}$ (final concentration: $4 \mathrm{mM}$ ), $60 \mu \mathrm{l}$ of recombinant human MPO (rhMPO) $92.4 \mathrm{U} / \mathrm{ml}$ (final relative activity: $2.6 \mathrm{U} / \mathrm{mg} \mathrm{LDL}$ ), a volume containing $1600 \mu \mathrm{g} L D L$ and $40 \mu \mathrm{l}$ of $\mathrm{H}_{2} \mathrm{O}_{2} 50 \mathrm{mM}$ (final concentration: $1 \mathrm{mM}$ ). The volume was adjusted to $2 \mathrm{ml}$ with $\mathrm{PBS}$ at $\mathrm{pH}$ 6.5. The oxidation reaction for the generation of MoxLDL was immediately performed at $37{ }^{\circ} \mathrm{C}$ for $5 \mathrm{~min}$ and stopped by incubation on ice to inhibit the MPO enzymatic activity. NatLDLs, OxLDLs and MoxLDLs were desalted against DMEM without glutamine (Cambrex, Belgium) by using PD-10 desalting columns (GE Healthcare). LDLs were sterile filtered $(0.2 \mu \mathrm{m})$, stored in the dark at $4{ }^{\circ} \mathrm{C}$ and used within 4 days. The LDL, OxLDL and MoxLDL concentration was determined by the Lowry method and used at a concentration of $100 \mu \mathrm{g} / \mathrm{ml}$.

\subsection{Cell treatment}

HMEC-1 were seeded in 12 well plates and treated in a time dependent manner with TNF $\alpha$ (10 ng/ml), IFN $\gamma(50 \mathrm{ng} / \mathrm{ml})$, Thrombin (2 $\mathrm{IU} / \mathrm{ml})$, MPO $(200 \mathrm{ng} / \mathrm{ml})$, MoxLDL $(100 \mu \mathrm{g} / \mathrm{ml})$, and OxLDL $(100 \mu \mathrm{g} /$ $\mathrm{ml}$ ) for 3,6,12 and $24 \mathrm{~h}$. Cells were also treated with VEGF $(100 \mathrm{ng} / \mathrm{ml})$ or FGF ( $50 \mathrm{ng} / \mathrm{ml}$ ) for $24 \mathrm{~h}$. The respective concentrations were selected 
according to physiological or pathological ranges found in the literature and already used in the laboratory (for examples see Refs. [16-20]). Furthermore, cells were treated for $24 \mathrm{~h}$ in a dose dependent manner with TNF $\alpha(1,5$ and $10 \mathrm{ng} / \mathrm{ml})$, IFN $\gamma(10,25$ and $50 \mathrm{ng} / \mathrm{ml})$, thrombin (0.5, 1 and $2 \mathrm{IU} / \mathrm{ml})$, MPO (50, 100 and $200 \mathrm{ng} / \mathrm{ml})$, MoxLDL/oxLDL (50, 100 and $200 \mu \mathrm{g} / \mathrm{ml})$, VEGF (10, 50 and $100 \mathrm{ng} / \mathrm{ml})$ and FGF $(5,10$ and $50 \mathrm{ng} / \mathrm{ml}$ ). These concentrations were selected according to a gradient increasing to the values selected above.

\subsection{RNA extraction and quantitative real-time PCR}

Total RNA was extracted from cells using silica-membrane spin columns (RNeasy Mini Kit, Qiagen) according to the manufacturer's instructions. Total RNA concentrations and A260/A280 and A260/230 ratios were assessed using spectrophotometry (NanoDrop $2000^{\circ}$, Thermo Scientific). A260/280 ratios exceeded 2.0 in all samples. $1 \mu \mathrm{g}$ of total RNA was treated with DNAse and reverse-transcribed using PrimeScript RT reagent Kit (Takara- Clontech). Quantitative Real-Time PCR was performed using a LightCycler ${ }^{\circ} 480$ (Roche) apparatus and SYBR Green I Master (Roche). Primer sequences for target genes and reference genes (glyceraldehyde 3-phosphate dehydrogenase (GAPDH), 60 S ribosomal protein L27 ( $R P L-27)$ are listed in Supplementary Table 1. A control reaction was routinely performed in absence of RT to assess the presence of trace amounts of DNA and always proved negative. The conditions used for qPCR were: initial denaturation step at $95^{\circ} \mathrm{C}(5 \mathrm{~min})$, followed by 50 amplification cycles $\left(15 \mathrm{~s}\right.$ at $95^{\circ} \mathrm{C}, 30 \mathrm{~s}$ at $58^{\circ} \mathrm{C}$ (annealing) and $30 \mathrm{~s}$ at $72^{\circ} \mathrm{C}$ (elongation). mRNA expression for each gene was determined using the delta CT method and was normalized against the geometric mean of GAPDH and RPL27.

\subsection{Western blot}

A total of $10^{6}$ cells for each treatment were pelleted and lysed in RIPA lysis buffer (Sigma) supplemented with protease inhibitor cocktail (Roche). Cell lysates were centrifuged at $12000 \mathrm{~g}, 4^{\circ} \mathrm{C}$ for $15 \mathrm{~min}$ and protein concentration was measured using bicinchoninic acid assay kit (ThermoFisher). Proteins were separated by SDS-PAGE in reducing conditions and transferred to nitrocellulose membrane (GE Healthcare Life Sciences). After saturation with $5 \%$ milk, the membrane was incubated overnight at $4{ }^{\circ} \mathrm{C}$ with the appropriate primary antibody: antiPhospho ERK1/2 1:5000, anti-total ERK 1/2 (1:10000), anti-Phospho Akt (1:5000), anti-total Akt (1:10000), anti-Phospho FAK (1:1000), and anti-total FAK (1:1000) (Abcam), anti-APOL1 (1/1000), anti-APOL2 (1/ 2000), anti-APOL3 (1/2500) and anti-APOL6 (1/500) (sigma), washed, then incubated with (HRP) conjugated secondary antibody for $1 \mathrm{~h}$ at room temperature and revealed using the ECL substrate (PerkinElmer). Monoclonal anti- $\beta$-actin antibody $(1 / 80000$; Sigma) was used for protein loading control. Densitometric analysis was performed using ImageJ.

\subsection{Tube formation (tubulogenesis) assay for in vitro angiogenesis on matrigel and collagen gel}

The $\mu$-slide Angiogenesis System (Ibidi) was used to assess the formation of tube-like structures according to the manufacturer's instructions. Briefly, $\mu$-slide wells were coated with $10 \mu \mathrm{l}$ of growth factor reduced matrigel (ThermoFisher), then allowed to polymerize for $30 \mathrm{~min}$ at $37^{\circ} \mathrm{C}$. For collagen gel experiments, $4 \mathrm{mg} / \mathrm{ml}$ collagen Type I stock solution was diluted to the desired final concentration $(2.5 \mathrm{mg}$ / $\mathrm{ml}$ ) by gently mixing with PBS and distilled water on ice and neutralized to $\mathrm{pH} 7.0$ with $1 \mathrm{~N} \mathrm{NaOH}$. $10 \mu$ l of the mixture was seeded into $\mu$-slide wells and allowed to polymerize for $1 \mathrm{~h}$ at $37^{\circ} \mathrm{C}$.

$10^{4}$ cells in $50 \mu 1$ media (either supplemented with VEGF, MPO and thrombin or not) were seeded per well, incubated at $37^{\circ} \mathrm{C}, 5 \% \mathrm{CO}_{2}$ and inspected for tubule formation after 6 or $24 \mathrm{~h}$. Pictures were taken from different fields with the $10 \times$ objective using phase contrast microscopy
(Nikon, Eclipse Ti). Vessel morphometric parameters including vessel length and junction density were measured using AngioTool software. Experiments were reproduced 3 times independently.

\subsection{Scratch assay}

EC migration was monitored using the scratch assay. Briefly, $3.10^{4}$ cells were seeded into 2 well silicone inserts defining a cell-free gap (Ibidi) and incubated overnight in growth medium at $37^{\circ} \mathrm{C}, 5 \% \mathrm{CO}_{2}$ to allow the cells to attach and to form a confluent monolayer. Inserts were then removed allowing cells to migrate and fill the gap, and fresh growth medium was added. Scratch width was photographed at different time points $(0,3,6$ and $12 \mathrm{~h})$ from three fields of view with the $10 \times$ objective using light microscopy (PixeLINK PL-A642 Megapixel FireWire Camera). The experiments were performed in duplicate. Using the Image $J$ software, The cell-free wound surface was measured between the wound edges, averaged between the fields of views and duplicates and expressed as a percentage of the initial wound width at $\mathrm{t}=0 \mathrm{~h}$.

\subsection{Endothelial permeability assay}

Endothelial permeability was assayed using the Millipore in vitro vascular permeability kit according to the manufacturer's instructions. Briefly, HMEC-1 WT and APOL3 KO cells were seeded on porous $(1 \mu \mathrm{m}$ pores) polyethylene terephthalate membranes in the upper chamber of transwell inserts at $80 \%$ confluence. They were allowed to grow for $48 \mathrm{~h}$ to reach confluence and contact inhibition. The medium was changed and cells were mock- or TNF $\alpha$-treated for $24 \mathrm{~h}$. FITC-dextran (MW: 3000Da) was then added in the insert upper chamber for $20 \mathrm{~min}$. The medium was then removed from the well (bottom chamber) and fluorescence was immediately measured by a fluoromax 4 Horiba spectrofluorometer using excitation filters at $485 \mathrm{~nm}$ and emission filters at 517 and $535 \mathrm{~nm}$. Results were harvested as arbitrary fluorescence units of fluorescence/0,1 s. Endothelial cells were then washed and stained. All the wells' surfaces were carefully observed under bright field microscope in order to ensure endothelium monolayer integrity.

\subsection{Cell proliferation assay}

\subsubsection{WST-1 cell proliferation assay}

Cell proliferation was evaluated using Cell Proliferation Reagent WST-1 (Sigma) according to the manufacturer's instructions. This assay is based on the measurement of the glycolytic production of NADH directly correlated to the number of active cells. Briefly, $25.10^{3}$ cells were cultured in growth medium for $24 \mathrm{~h}$ at $37^{\circ} \mathrm{C}, 5 \% \mathrm{CO}_{2} .10 \mu \mathrm{l}$ of WST-1 reagent were added per well and the formazan dye production (by an NADH dependent reduction of tetrazolium salt) was quantified with a spectrophotometer.

\subsubsection{CFSE cell proliferation assay}

HMEC- 1 cells were seeded at $2.10^{5}$ cells/well in a 6 well plate. After $24 \mathrm{~h}$, cells were treated with pre-warmed PBS containing CFDA-SE (final concentration $10 \mu \mathrm{M}$ ) for $15 \mathrm{~min}$ at $37^{\circ} \mathrm{C}$ to allow dye uptake. The loading solution was removed and cells were incubated with fresh prewarmed culture medium for an additional $30 \mathrm{~min}$ to allow the dye to react with intracellular proteins before flow cytometry analysis. Cells were then further incubated for desired periods of time (24, 48, 72 and $96 \mathrm{~h}$ ) to allow cells to divide and analyzed again by flow cytometry.

\subsubsection{Cell counting by flow cytometry}

HMEC- 1 cells were seeded at a concentration of $2.10^{5}$ cells/well in 6 well plates. Cells were trypsinized and counted at times 0, 24, 48, 72 and $96 \mathrm{~h}$. 
A

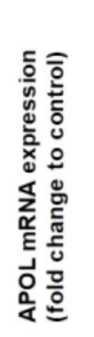

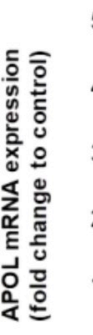

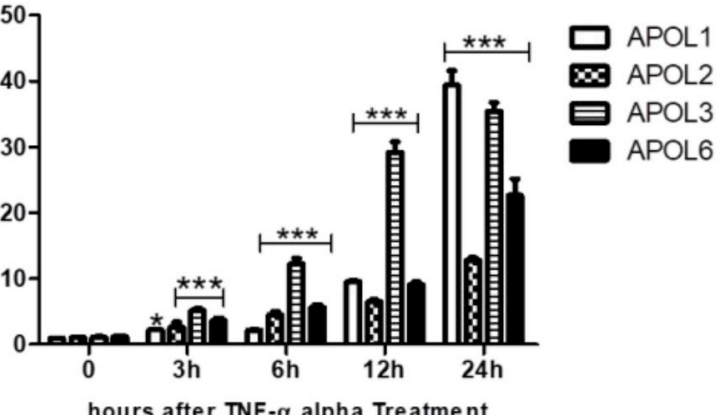

$\begin{array}{lllll}0 & 3 & 6 & 12 & 24\end{array}$

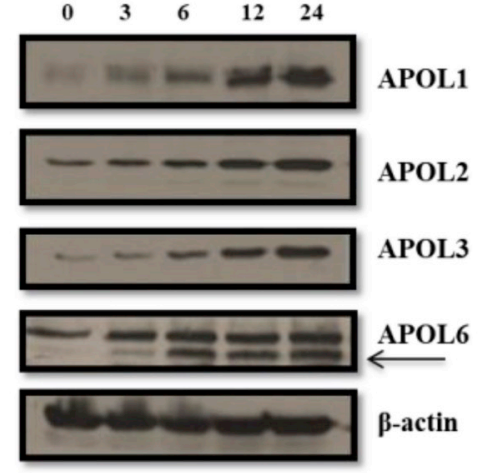

C

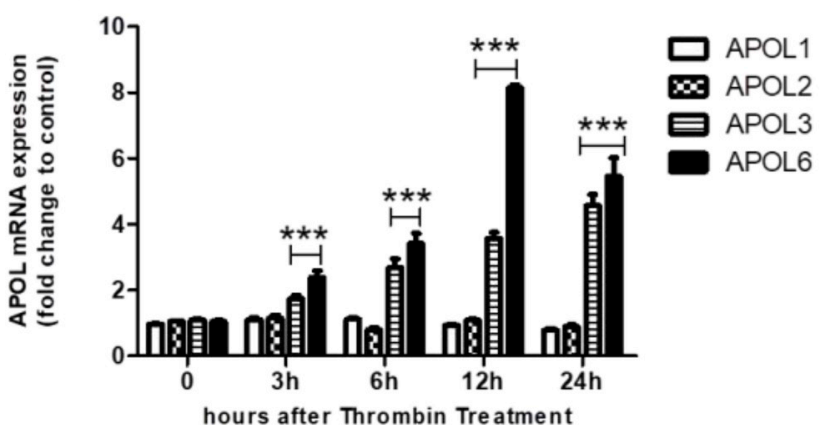

hours after Thrombin Treatment

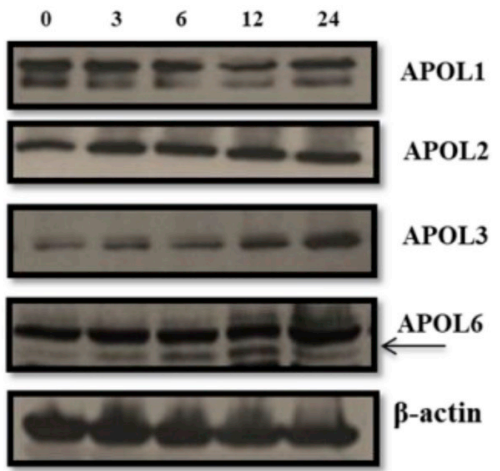

B
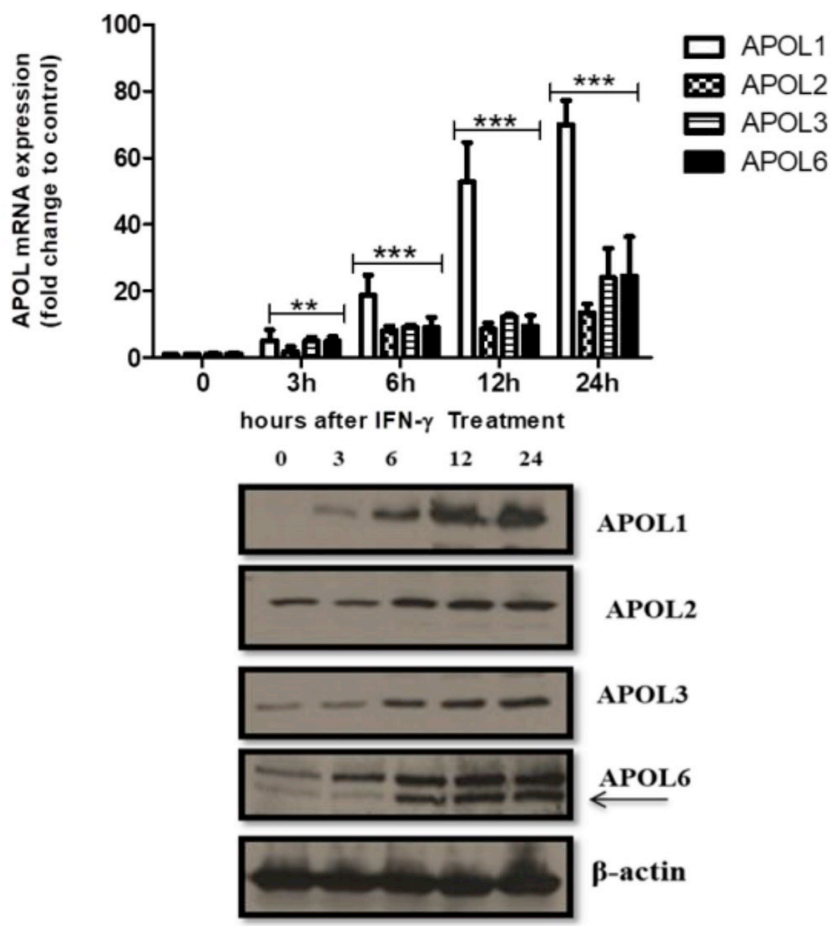

D
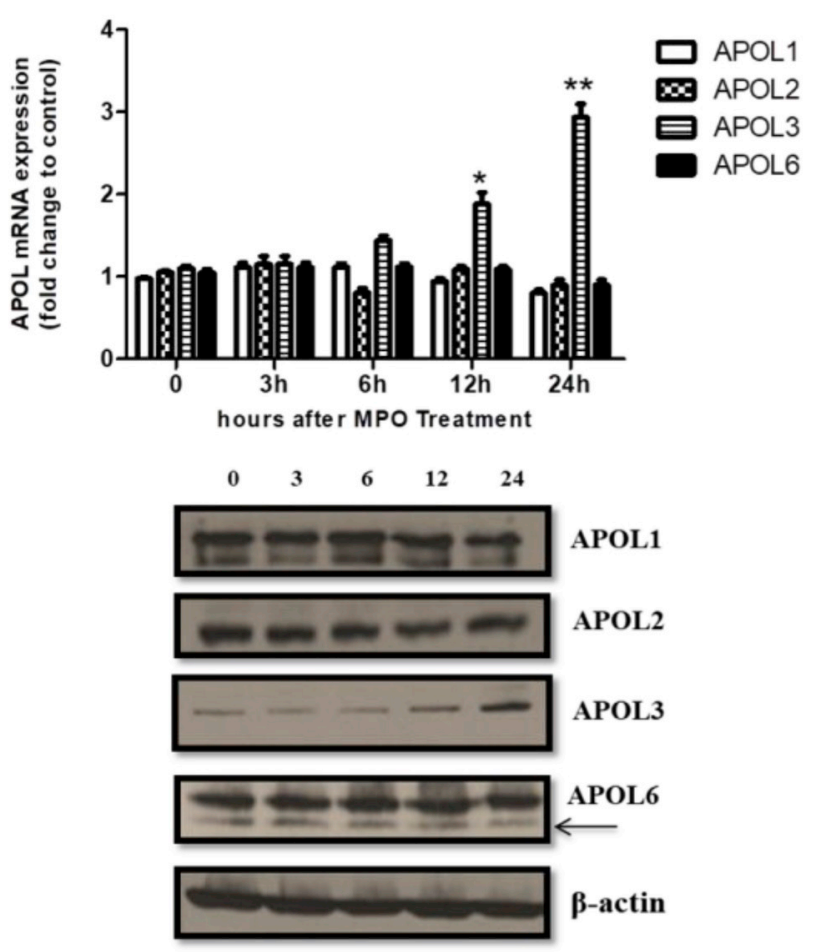

Fig. 1. APOLs mRNA and protein expression levels in treated HMEC-1.

HMEC-1 cells were treated for the indicated times with TNF- $\alpha(10 \mathrm{ng} / \mathrm{ml})(\mathrm{A}), \mathrm{IFN}-\gamma(50 \mathrm{ng} / \mathrm{ml})(\mathrm{B})$, thrombin (2 IU/ml) (C), MPO (200 ng/ml) (D), MoxLDL (100 $\mu$ / $\mathrm{ml})(\mathrm{E})$, oxLDL $(100 \mu \mathrm{g} / \mathrm{ml})(\mathrm{F})$, VEGF $(100 \mathrm{ng} / \mathrm{ml})(\mathrm{G})$ and FGF $(50 \mathrm{ng} / \mathrm{ml})(\mathrm{H})$. RNA was extracted and analyzed by qRT-PCR using specific primers for APOL1, APOL2, APOL3 and APOL6. The expression level was normalized to the geometric mean of GAPDH and RPL27. Values were expressed as fold change over control. The arrow points at the APOL6-specific band. Data were evaluated by two-way ANOVA test followed by Bonferroni's Multiple Comparison Test. (* $p<0.05$, $* * p<0.01$, $* * * p<0.001)$. For protein analysis, cells were lysed and analyzed by Western blot using specific anti-APOL1, anti-APOL2, anti-APOL3, anti-APOL6 antibodies and anti- $\beta$-actin as loading control. 


\subsection{Software tools}

\subsubsection{AngioTool}

The AngioTool software [21] is an open source validated tool that allows quantifications of different morphological parameters by assessing the variation in foreground and background pixel density across a microscopic image.

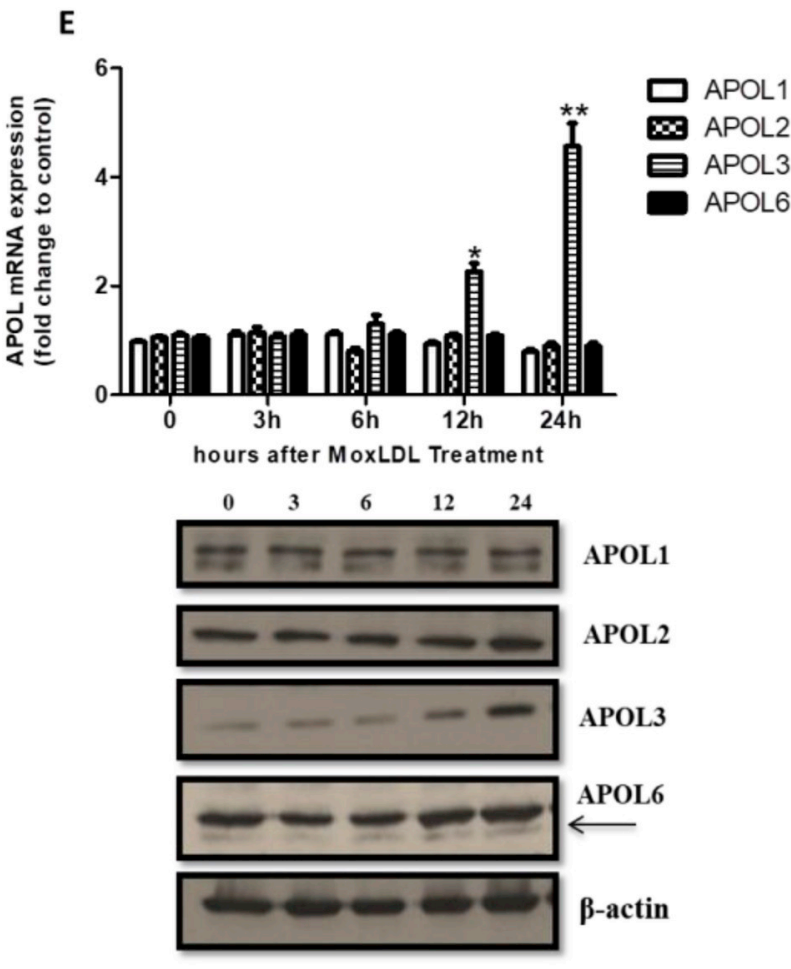

$\mathbf{G}$

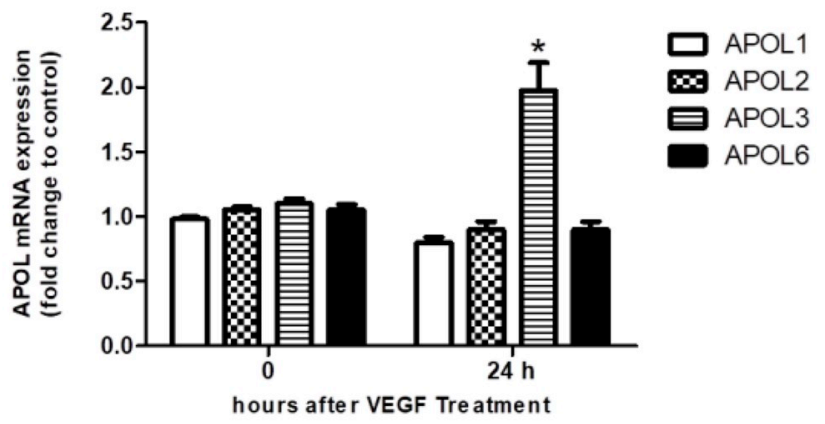

\subsubsection{Image $J$}

Image $\mathrm{J}$ software is a tool allowing image analysis and processing, written and maintained by Wayne Rasband of NIH.

\subsection{Statistics}

Data were expressed as mean \pm standard error of mean (SEM). For
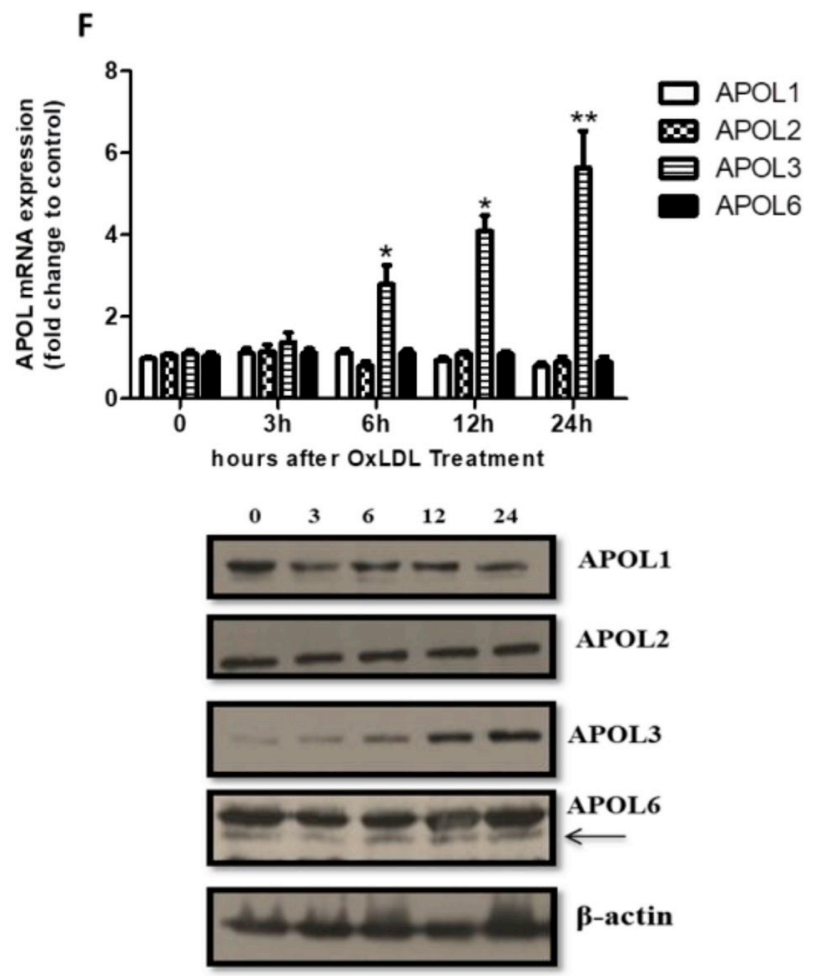

H

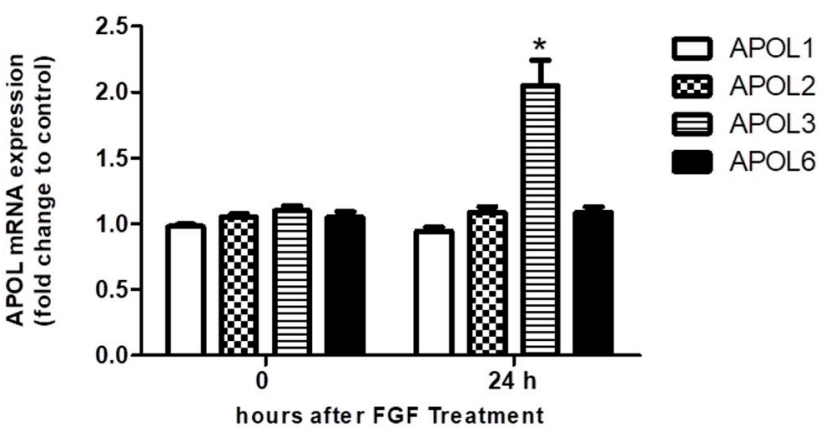

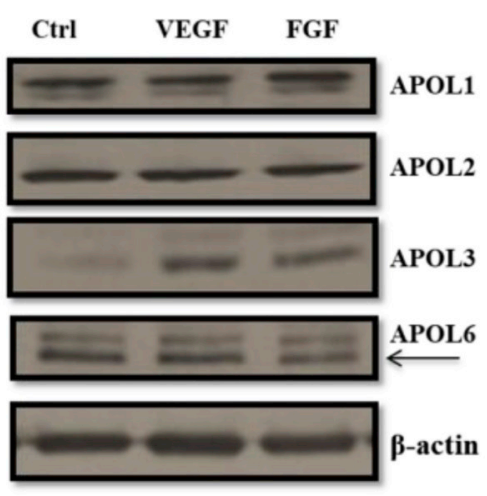

Fig. 1. (continued) 
two group comparison, unpaired $t$-test was used. Differences between multiple groups were evaluated using one-way or two-way ANOVA as appropriate, followed by Bonferroni post-hoc test for multiple

A

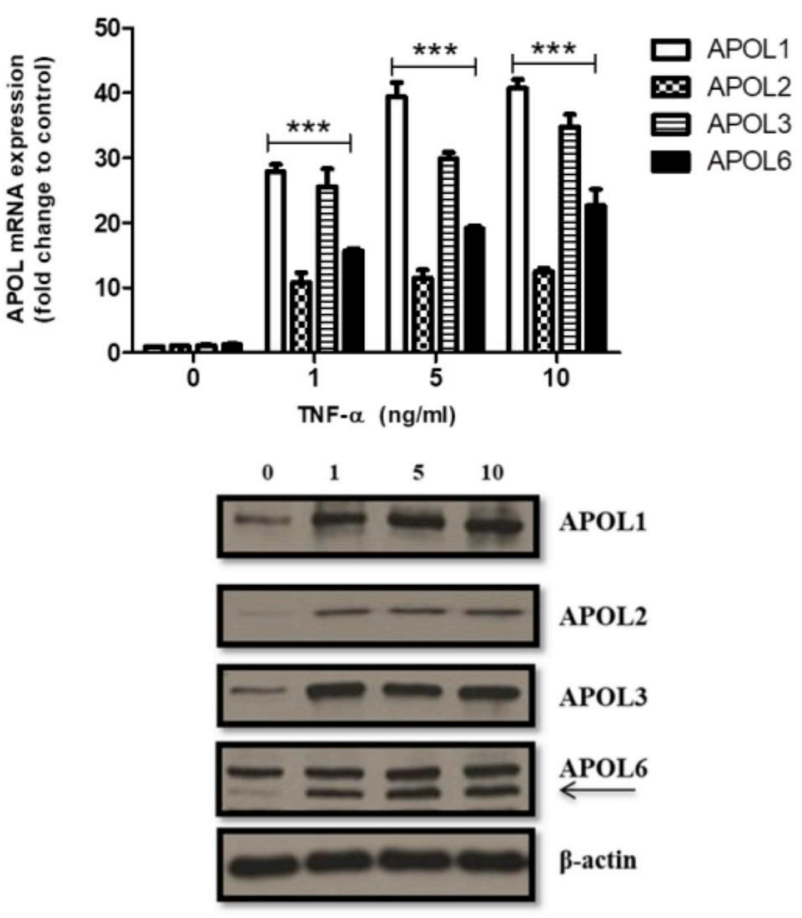

C
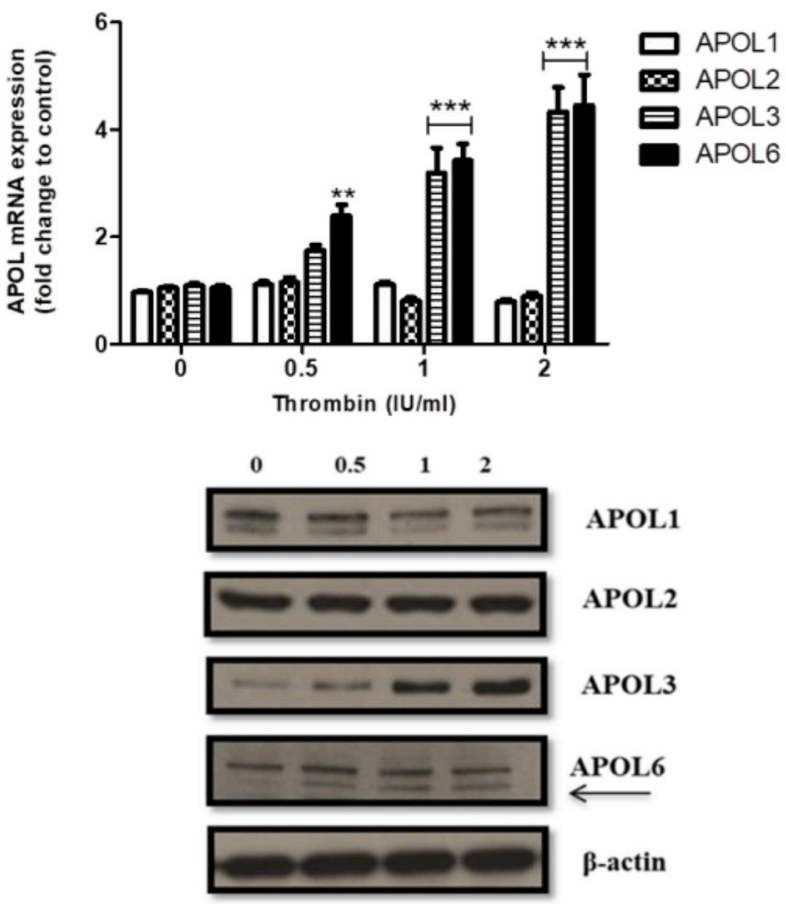

comparisons. Normal distribution of data sets was estimated using the Kolmogorov-Smirnov test. The significance level was chosen as $p$ value: $<0.05(*),<0.01(* *)$, and $<0.001(* * *)$. All calculations were
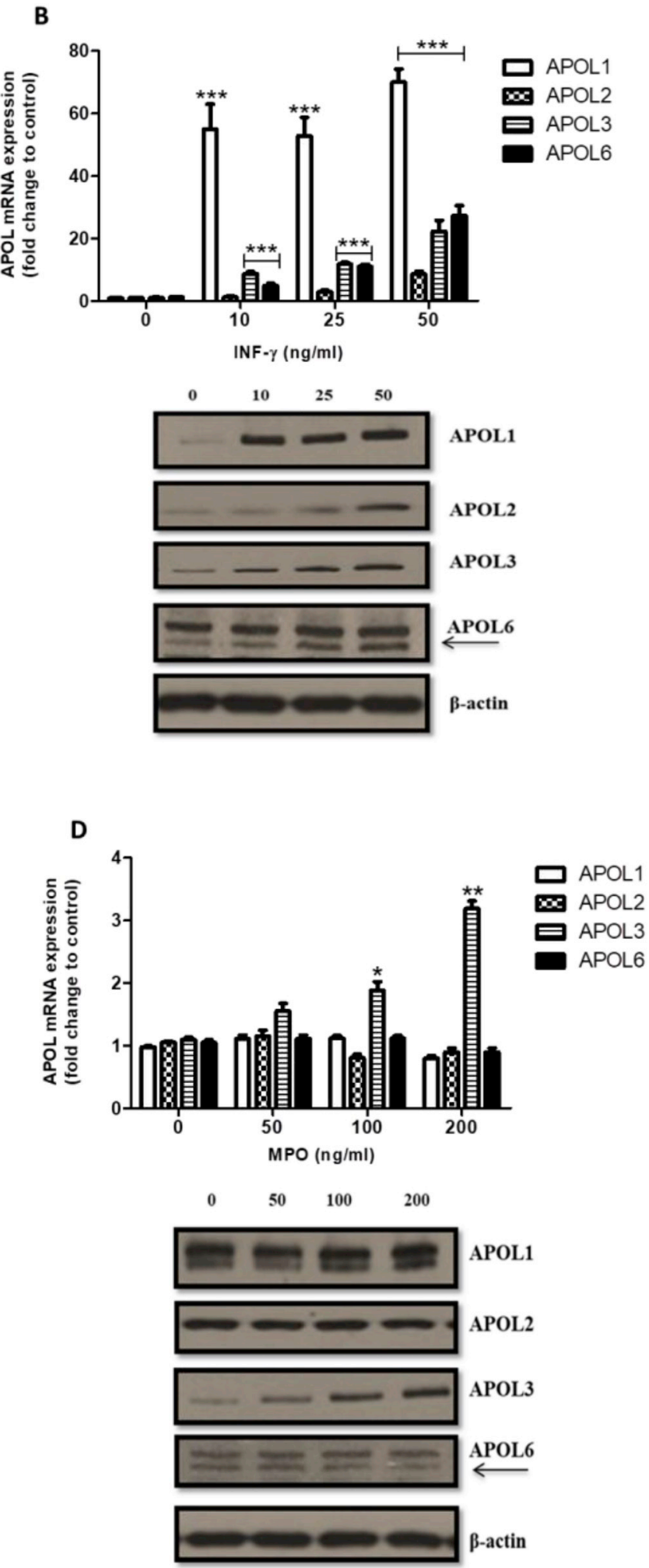

Fig. 2. APOLs mRNA and protein expression levels in treated HMEC-1.

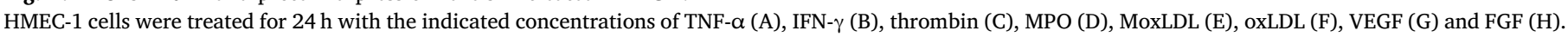

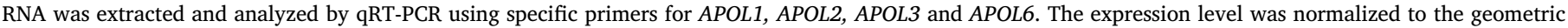

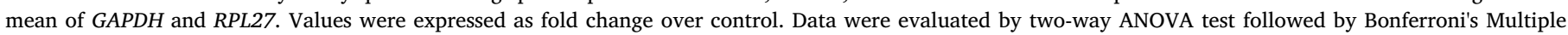

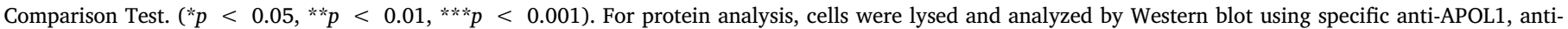
APOL2, anti-APOL3, anti-APOL6 antibodies and anti- $\beta$-actin as loading control. 

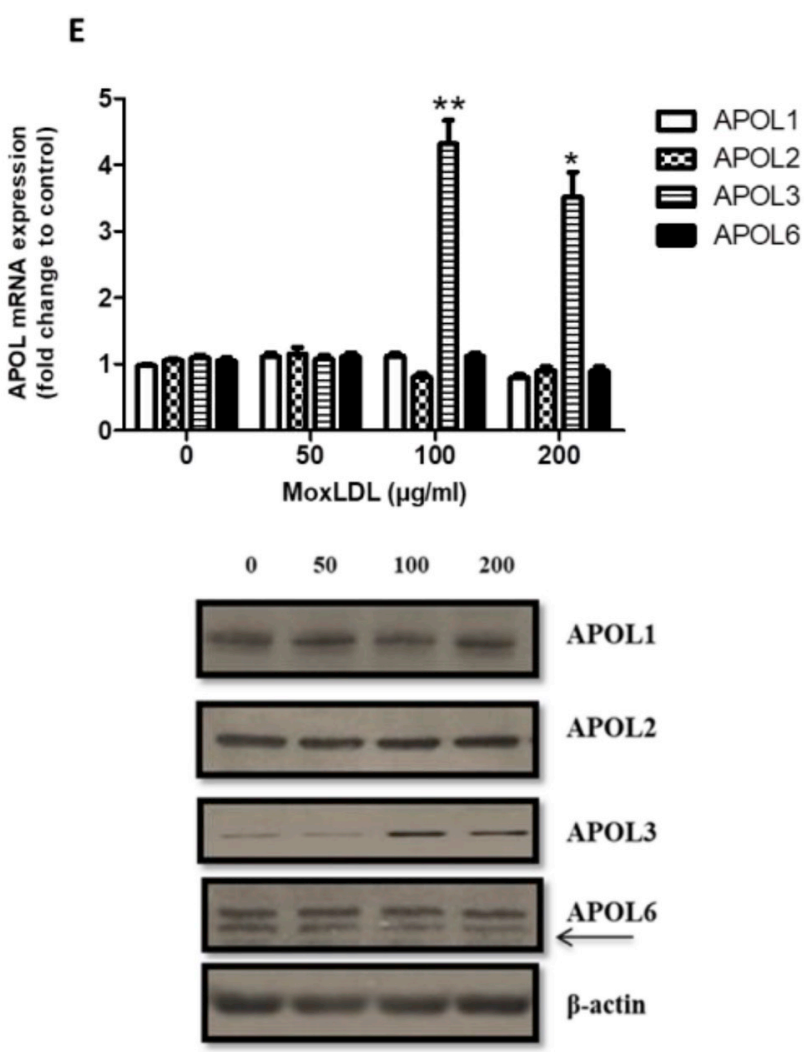

G
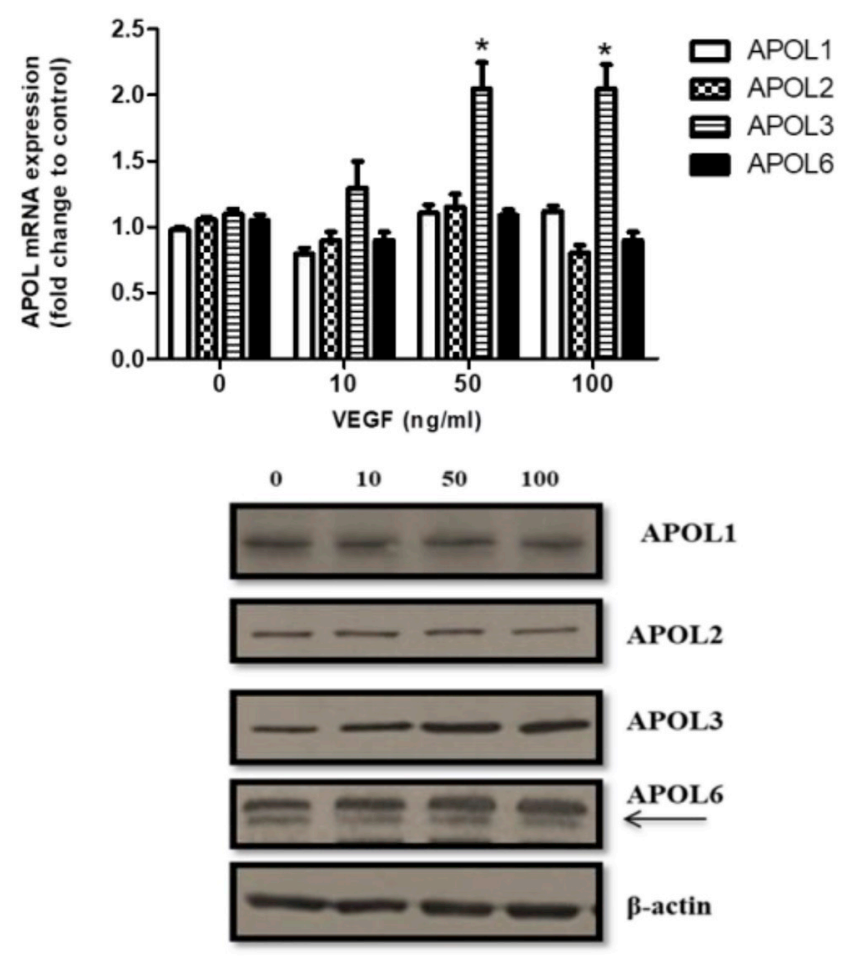
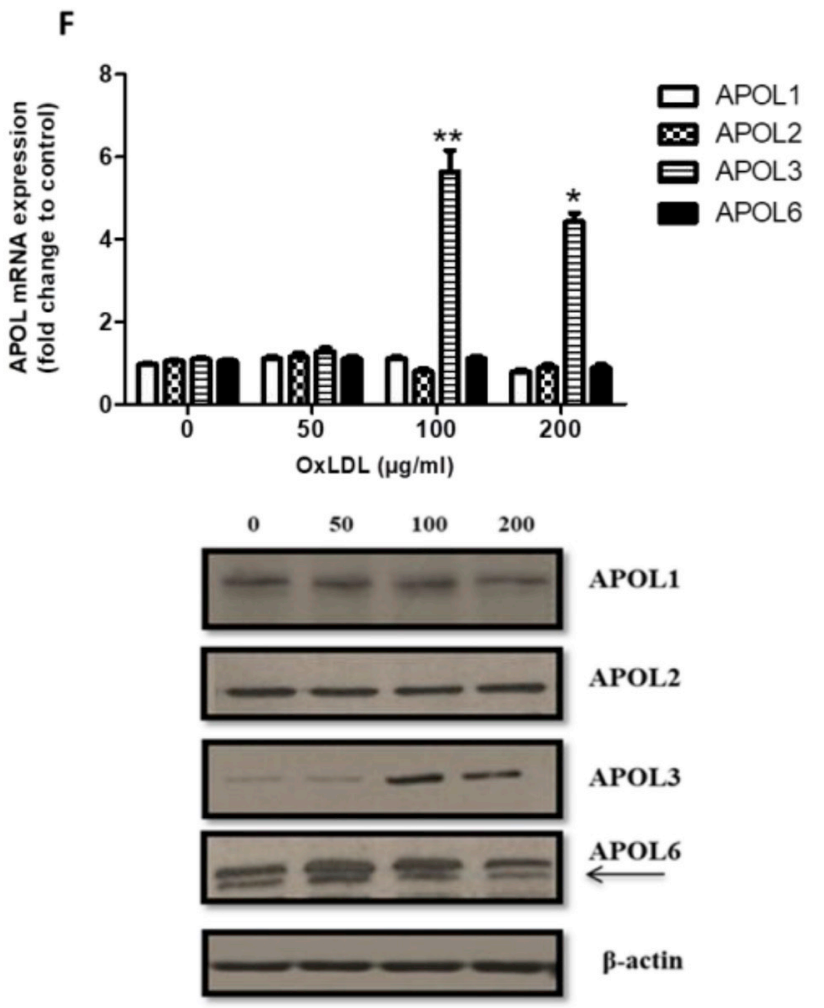

H
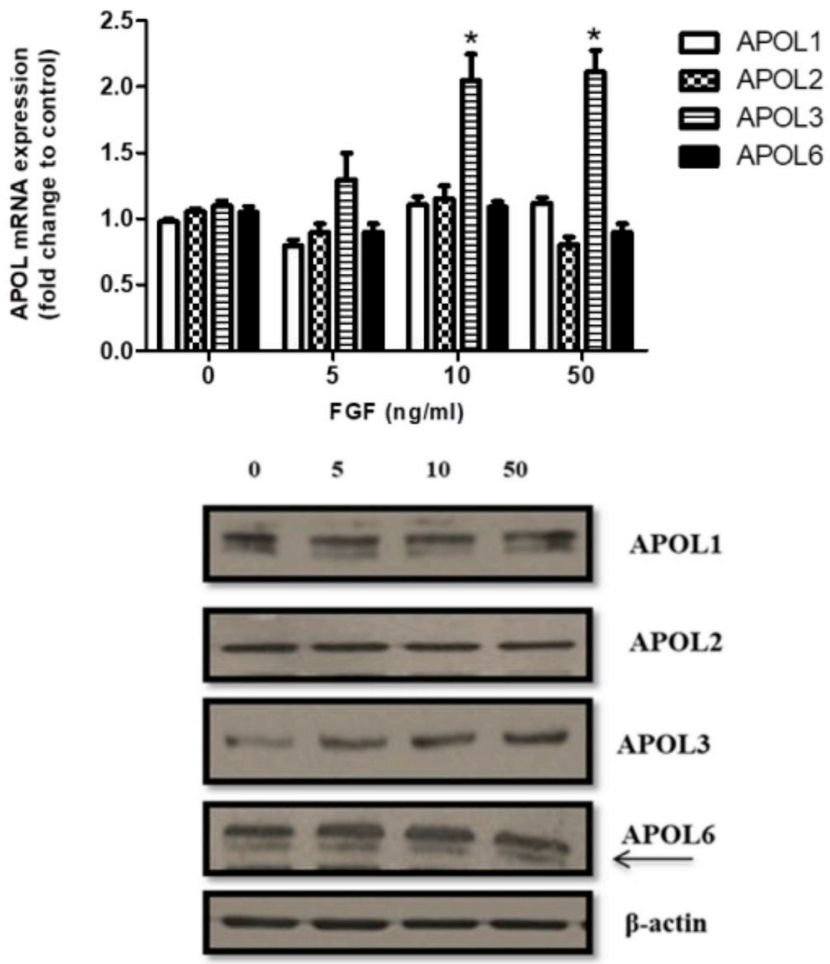

Fig. 2. (continued) 
A WT

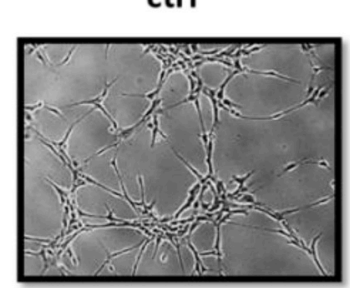

Аз ко
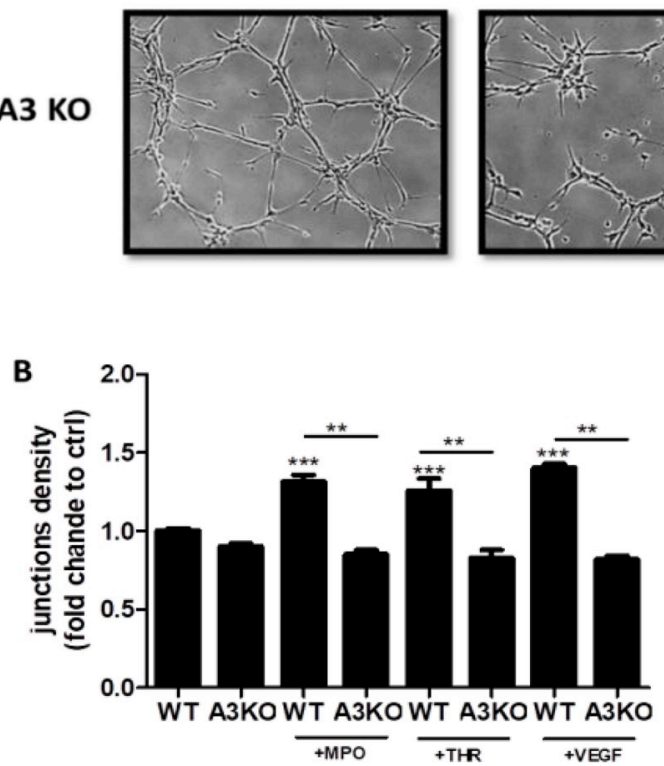

D

ctrl
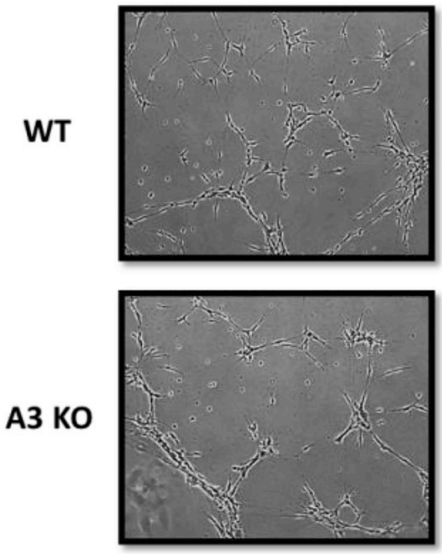

E

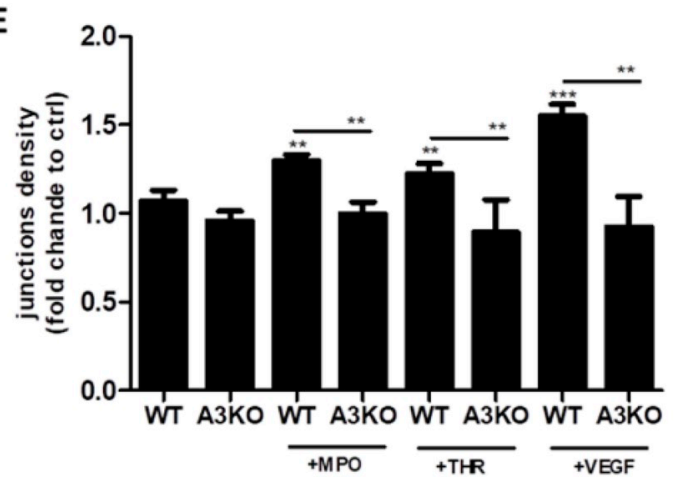

+THR
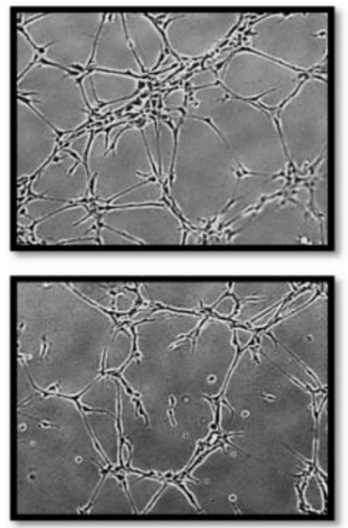

+VEGF
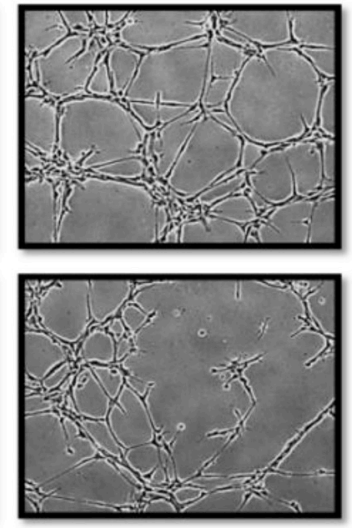

C

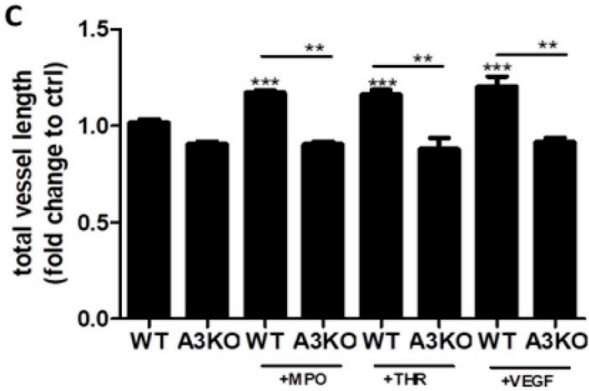

+THR

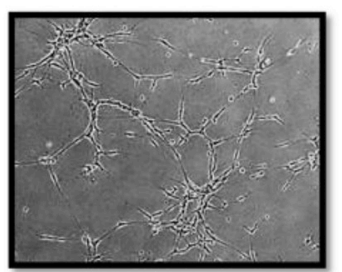

+VEGF
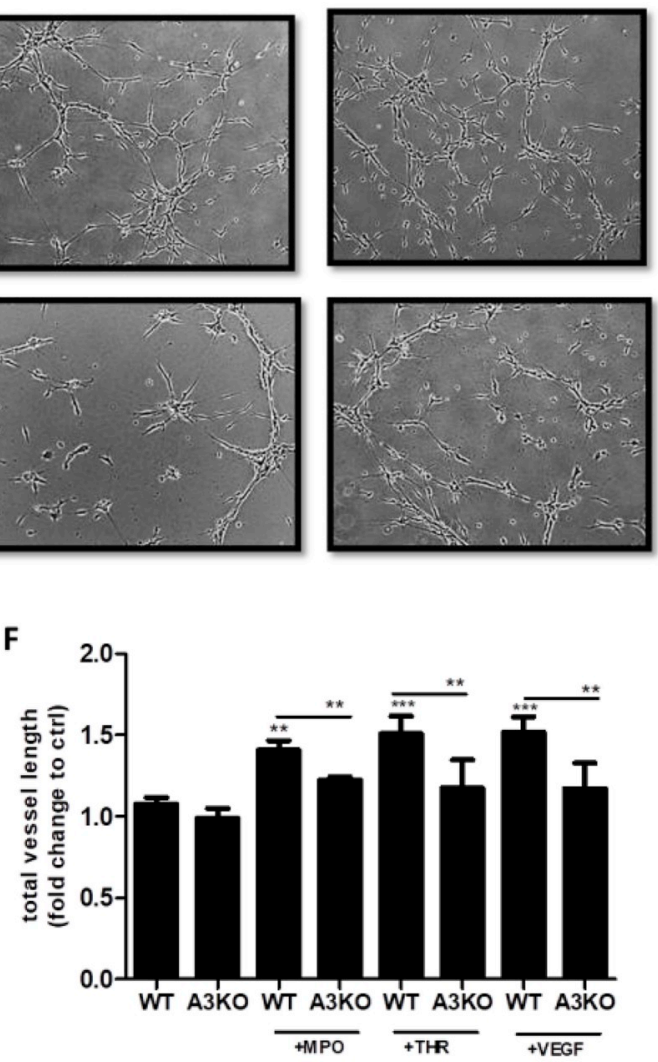
Fig. 3. Tubulogenesis in APOL3 KO cells.

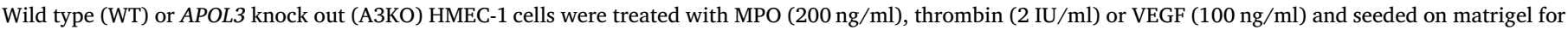

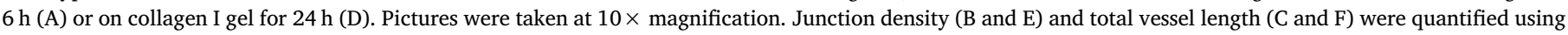

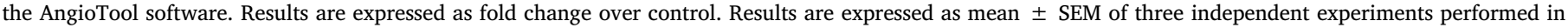
triplicate. Statistics were performed using one-way ANOVA, followed by Bonferroni's Multiple Comparison Test. ( $\left.{ }^{*} p<0.05,{ }^{* *} p<0.01, * * * p<0.001\right)$.

performed with GraphPad Prism 5.01.

\section{Results}

\subsection{Inflammatory stimuli induced the expression of APOL family members}

The endothelial expression of some members of the APOL family as well as their induction by pro-inflammatory cytokines (TNF- $\alpha$ and IFN$\gamma)$ has already been reported $[12,13]$. We asked whether other pro-inflammatory stimuli involved in endothelial dysfunction or atherosclerosis would also be able to do so. Thus we submitted HMEC-1 cells to several treatments according to both time kinetics and concentration gradient. As illustrated in Figs. 1 and 2, TNF- $\alpha$ and IFN- $\gamma$ were confirmed to induce APOL1, 2, 3 and 6 RNA and protein expression, although with different intensity. For example, after a $24 \mathrm{~h}$ treatment, TNF- $\alpha(10 \mathrm{ng} / \mathrm{ml})$ induced APOL1, 2, 3 and 6 RNA expression by 40,12,25 and 25 times respectively (Fig. $1 \mathrm{~A})$, while IFN- $\gamma(50 \mathrm{ng} / \mathrm{ml})$ induced APOL1, 2, 3 and 6 RNA expression by 60,12,20 and 20 times respectively (Fig. 1B). The inductions by TNF- $\alpha$, IFN- $\gamma$ and thrombin followed a similar kinetics, APOLs being induced as early as at $3 \mathrm{~h}$ and the induction increasing until $24 \mathrm{~h}$. Expression of all corresponding proteins was also induced to a similar extent. Thrombin significantly induced APOL3 and 6 expression (Fig. 1C), while MPO (Fig. 1D), MoxLDL (Fig. 1E) and OxLDL (Fig. 1F) only induced APOL3 expression. These inductions however happened to a much lower extent. APOL3 induction by MPO, MoxLDL and OxLDL was delayed at $12 \mathrm{~h}$ ( $6 \mathrm{~h}$ in the last case). Treatments with growing concentrations of each of the inducers did not affect these conclusions. In general, increasing concentrations enhanced the extent of induction (Fig. 2) although with different dose effects. Thus, maximal induction of the 4 APOLs was reached at the lower TNF- $\alpha$ concentration (Fig. 2A). While all APOLs except APOL2 were induced at the lowest IFN- $\gamma$ concentration, APOL1 induction was stronger (Fig. 2B). Inductions by thrombin and MPO were progressive (Fig. 2C and D). In the case of MoxLDL and OxLDL, there was an induction threshold between $50 \mathrm{ng} / \mathrm{ml}$ and $100 \mathrm{ng} / \mathrm{ml}$ (Fig. 2E and F).

\subsection{APOL3 is the only APOL induced by VEGF and FGF}

We also assessed the effect of two well-known pro-angiogenic inducers (VEGF and FGF) on the expression of APOLs in HMEC-1 cells. Figs. 1 and 2 show that after $24 \mathrm{~h}$ both VEGF (Fig. 1G) and FGF (Fig. 1H) induced exclusively APOL3 (but not other family members) by 2 times. This induction required concentrations approaching the reported physiological concentrations $[17,22]$ as it did not work at lower concentrations (Fig. 2G and $\mathrm{H}$ ).

\subsection{APOL3 knock out clones}

As all the above treatments induced APOL3 expression, some specifically, and as several of these are known to interfere with various aspects of endothelial function, for example tubulogenesis and/or cell motility, we decided to investigate whether APOL3 is involved in these cell behaviors. For that purpose we set out to knock out the alleles of the APOL3 gene in HMEC-1 cells using the CRISPR/Cas9 technology. Thus, after transfection of the RNA guide/Cas9 expressing construct, selection of transfected fluorescent cells, cloning, western blot analysis and genome sequencing, several clones where APOL3 protein expression was lost were selected. Supplementary Fig. S1 shows the characterization by Western blot of APOL3 clone 26 (APOL3 knock out A3KO). In this particular case, the two alleles were found mutated (one by a one nucleotide insertion and the other by a 4 nucleotide deletion) generating heterozygous frame shifts, and giving rise to stop codons downstream of the RNA guide hybridization site (Supplementary Fig. S2).

\subsection{APOL3 is involved in the angiogenic phenotype}

In order to assess the role of APOL3 in the formation of a vascularlike network by endothelial cells, APOL3 knock out (A3KO) cells as well as wild type HMEC-1 cells (WT) were then analyzed in a tubulogenesis assay. Cells were originally seeded on matrigel or collagen I coated plates for $6 \mathrm{~h}$ and $24 \mathrm{~h}$ respectively. As expected, HMEC- 1 formed a capillary like network. However, as illustrated in Fig. 3 (first columns in panels A and D), invalidation of APOL3 only slightly interfered with tubule formation, a statistically non-significant change as confirmed by image analysis and quantification (Fig. 3B, C, E and F). As MPO, Thrombin and VEGF all induced APOL3 expression and tubulogenesis, we also assessed the role of APOL3 on tubule formation under these treatments. As illustrated in Fig. 3A and D and quantified in Fig. 3B, C, $\mathrm{E}$ and F APOL3 invalidation partially inhibited the stimulation of tubular network formation both in terms of cumulative vessel length and junction density. The nature of the matrix supporting tubulogenesis (whether matrigel or collagen) did not affect these observations although tubule formation was lesser in the collagen matrix.

\subsection{APOL3 KO interferes with scratch closure}

Together with tubule network formation, angiogenesis also requires cell migration. In order to assess cell motility, HMEC-1 cells were seeded and grown until confluence into culture wells equipped with a device drawing a linear denudation zone. The device was removed and cells at the edge of the wound were therefore allowed to migrate and colonize the denudation zone. Cell free surfaces were measured and measurements plotted against time. As illustrated in Fig. 4A and quantified in Fig. 4B, APOL3 invalidation lowered cell motility by $20 \%$.

Proliferation assays illustrated in Fig. 5 performed on the same cells indicated that the generation time of KO cells was the same than the wild type cells. This suggests that the effects observed on tubulogenesis and cell migration are not trite effects mediated by slow growth.

\subsection{APOL3 KO increases endothelial permeability}

Several of the factors increasing APOL3 expression in HMEC-1 endothelial cells (such as TNF- $\alpha$, IFN- $\gamma$, VEGF or thrombin) have been reported to influence endothelial permeability [23-26]. In order to assess a possible role of APOL3 in this property, HMEC-1 cells were seeded on porous membranes in the upper chamber of well inserts and allowed to grow until contact inhibition. Cells were mock or TNF- $\alpha$ treated for $24 \mathrm{~h}$. FITC dextran was then added in the insert and allowed to permeate the endothelial monolayer for $20 \mathrm{~min}$. Endothelial permeability was then assessed by measuring fluorescence intensity in the lower chamber medium. As shown in Fig. 6, APOL3 KO correlated with a statistically significant rise in endothelial permeability, to the same extent as that provoked by TNF- $\alpha$ known to interfere with this property and used as positive control. 


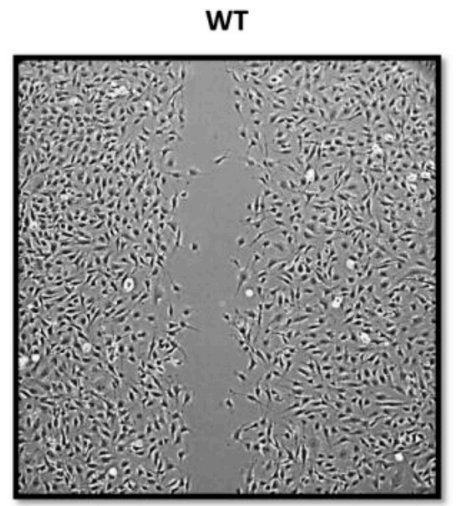

A3 KO

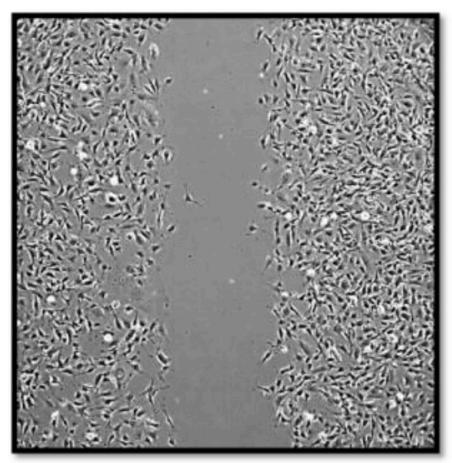

Fig. 4. Endothelial cell migration in APOL3 KO cells. (A) Wild type (WT) or APOL3 knock out (A3KO) HMEC1 cells were seeded into 2 well culture insert and allowed to migrate for $12 \mathrm{~h}$. Micrographs were taken at $10 \times$ magnification. (B) The relative change in cell-free gap surfaces was measured at different time points after removal of the wounding insert and expressed as fold change over control. Results are shown as mean \pm SEM of three independent experiments performed in duplicate. Statistics were performed using two-way ANOVA. $\left(p>0.05,{ }^{*} p<0.05\right.$, $* * p<0.01)$.

B

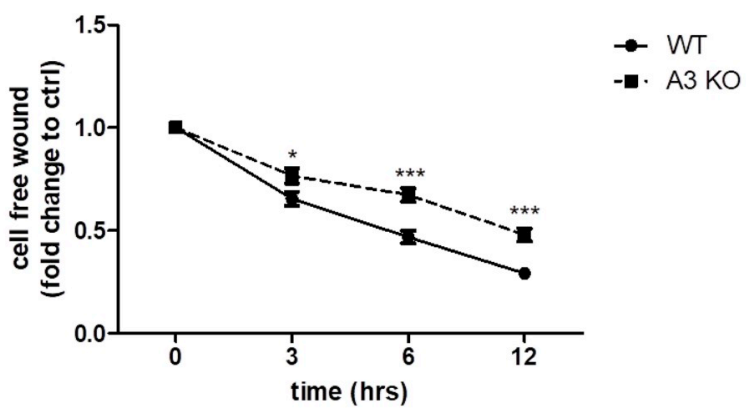

\subsection{APOL3 is a link in angiogenic pathways}

As tubulogenesis and wound healing are considered in vitro manifestations of in vivo angiogenic capabilities of EC, we asked whether APOL3 is involved in angiogenic signal transduction pathways. In agreement with such a role, VEGF, a well-known angiogenic factor, induced APOL3 expression (Figs. 1 and 2). We asked whether APOL3 is a link in VEGF or MPO elicited signal transduction pathways. Thus the phosphorylation state of kinases of angiogenic signal transduction pathways was compared in WT or KO cells stimulated by VEGF or MPO. The VEGF (as well as MPO) -dependent stimulation of ERK and FAK (but not Akt) phosphorylation was abolished in APOL3 KO cells. Indeed, MPO and VEGF both induce ERK, Akt and FAK phosphorylation by 1.5, 2.7, and 2.5 times respectively. APOL3 invalidation prevented the increase of ERK and FAK but not Akt phosphorylation. This suggested that APOL3 is associated to ERK and FAK but not Akt signal transduction (Fig. 7).

As these signal transduction pathways ultimately result in the control of angiogenic genes, we also analyzed APOL3 dependence of some of them. RNAs extracted from WT or A3KO HMEC-1, stimulated or not with MPO or VEGF were analyzed by qRTPCR using primers specific for 9 different angiogenic genes. Thus, HEY-1, PDGFB, ID-2, ID-3,IER2, NRARP, HES-1, SNAI and Cyr61 RNA expression was induced by ( 8 and 9)-fold, (3 and 3)-fold, (13 and 10)-fold, (9 and 7) -fold, (5 and 6)-fold, (3 and 3)-fold, (10 and 12) -fold, (12 and 15) and (2 and 2)-fold respectively upon MPO and VEGF treatment. The expression of $H E Y-1$ (Fig. 8A), PDGFB (Fig. 8B), ID2 (Fig. 8C) and ID3 (Fig. 8D) was down regulated in MPO and VEGF treated A3KO cells as compared to WT treated cells while the induction of the rest was not affected (Fig. 8). This suggested that APOL3 is involved in the transduction of part of the angiogenic pathways and some angiogenic genes.

\section{Discussion}

Our data suggest that APOL3 plays a role in endothelial function. In particular it is involved in angiogenic activities of EC such as capillary network formation, cell migration, angiogenic signal transduction pathways and angiogenic gene expression.

The endothelium is involved in the control of vascular functions. It participates in the regulation of fluid exchange, hemostatic balance, vascular tone and blood intercellular interactions. Furthermore it is de facto an actor in angiogenesis, the creation of new blood vessels. As a corollary, endothelium dysfunction correlates with a loss of regulation of these processes associated with several pathologies including cardiovascular disease (CVD) [1]. A pivotal role of inflammation is nowadays well admitted in the onset of CVD and cases of (inflammationdriven) angiogenesis and vessel repair [27]. EC are both actors and targets of inflammation related changes as they both express and react to some cytokines for example IL- 6 and IL- 8 or TNF- $\alpha$ and IFN- $\gamma$ respectively [28]. Among these cytokines, TNF- $\alpha$ and IFN- $\gamma$ modulate EC gene expression. In particular they induce the expression of members of a newly characterized family of apolipoproteins named the apoliporotein Ls (APOLs) [12,13]. The physiological roles of APOL proteins remain poorly known.

In this study, we confirmed the expression profile of APOLs in a model of endothelial cells (HMEC-1) in response to TNF- $\alpha$ and IFN- $\gamma$. We extended our observations to other inflammatory stimuli involved in cardiovascular diseases: oxLDL and MoxLDL, two pro-atherogenic molecules [29], thrombin a serine protease linking coagulation and inflammation [30], and myeloperoxidase an enzyme released by neutrophils at inflammation sites [29]. We analyzed the functional role of one of the family members in the endothelial phenotype.

Thus, TNF- $\alpha$ and IFN- $\gamma$ stimulated the expression of all analyzed APOLs, confirming observations previously made on another EC line, 
A

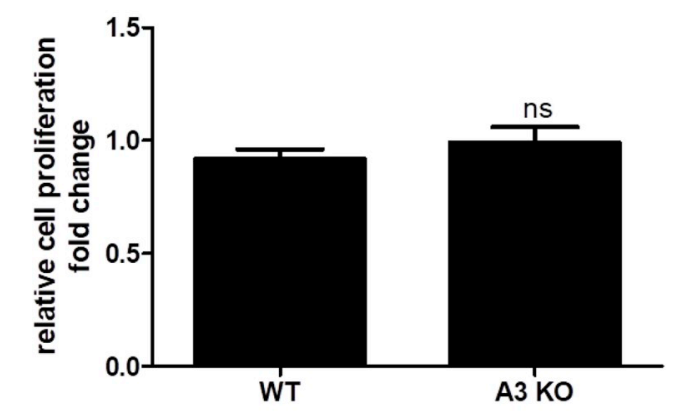

B

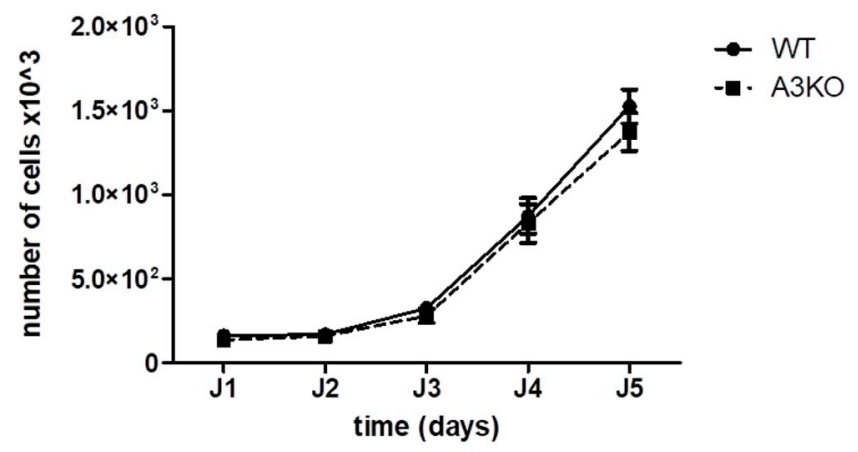

C

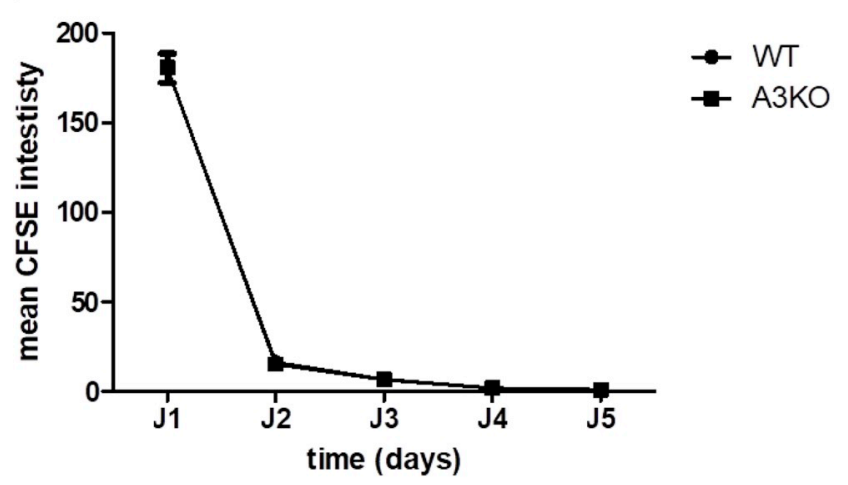

Fig. 5. Endothelial cell proliferation in APOL3 KO cells.

Wild type (WT) or APOL3 knock out (A3KO) HMEC-1 cell proliferation was evaluated using Cell Proliferation Reagent WST-1 after $24 \mathrm{~h}$. (A) or using flow cytometry analysis for cell count (B) and CFSE fluorescence (C) at $24 \mathrm{~h}$ intervals for 5 days. Results are shown as mean \pm SEM of three independent experiments performed in duplicate. Statistics were performed using unpaired $t$-test for WST-1 cell proliferation assay and two-way ANOVA for CFSE Cell Proliferation assay and cell counting. (ns: non-significant $p>0.05$, $* p<0.05, * *<0.01$ ).

HUVEC [12,13]. Thrombin only up-regulated APOL3 and APOL6 expression. Two modified LDL molecules (oxidized by different meansoxLDL and MoxLDL) and MPO exclusively induced the expression of one member of the family, APOL3. All the inducers were used at physiopathological concentrations supporting the relevance of our observations. This can only be compared to the only available very scarce in vivo or in vitro observations: APOL6 expression in SMCs in the neointima layer of atherosclerotic lesions [31]; APOL3 (CG12_1

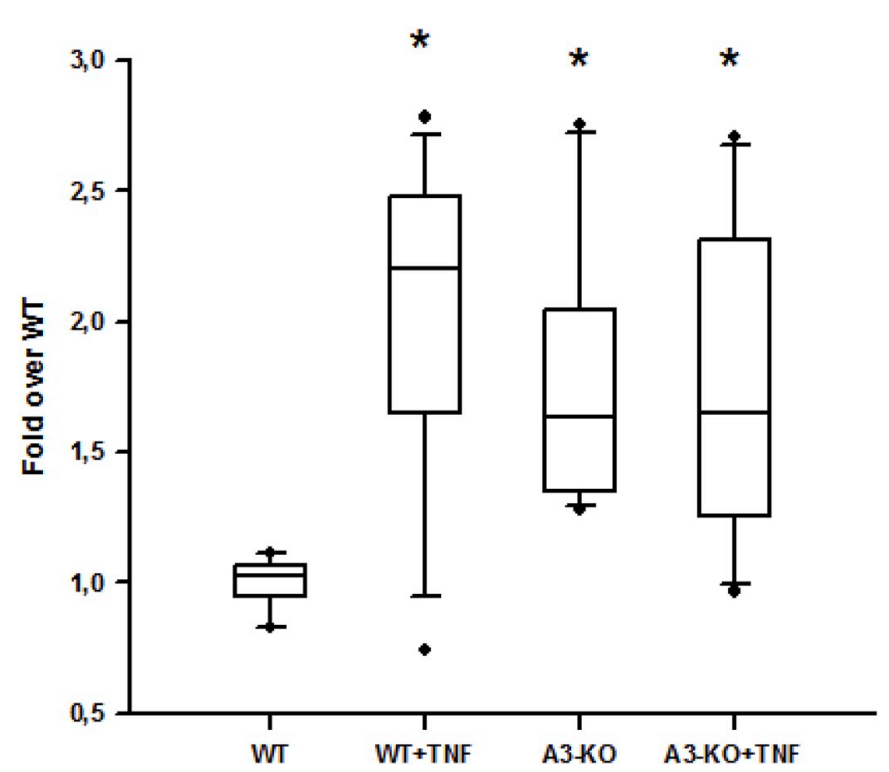

Fig. 6. Endothelial permeability in APOL3 KO cells.

Wild type (WT) or APOL3 knock out (A3KO) HMEC-1 cell were seeded on porous membranes in the upper chamber of transwell inserts and allowed to form a confluent monolayer. They were treated or not with TNF- $\alpha$. FITC dextran was added in the upper chamber and endothelial permeability was measured as fluorescence intensity in the lower chamber. Results are expressed as variation of fluorescence intensity over control (WT). Experiments were performed four fold in triplicate. Statistics were performed using Kruskal-Wallis One Way Analysis of Variance on Ranks $p<0.001$ ( ${ }^{*} p<0.05$ Tukey's post-hoc test).

(apolipoprotein-L like) in endothelial cells lining the normal and atherosclerotic iliac artery and aorta [32]; APOL3 in HUVEC treated with $3 \mathrm{MC}$ (3-methylcholanthrene) a toxic compound in cigarette smoke [33]. It was also reported that APOL3 is an activator of the transcription factor NF-kB that plays a pivotal role in immune and inflammatory responses [34]. Taken together, all these observations (including ours) are in agreement with a role of these two proteins (APOL3 and APOL6) in vascular inflammation. This does not exclude a possible role of APOL6 in programmed cell death as suggested in cancer cell line models [10].

While it is clear that inflammation has many consequences, as far as EC are concerned, there is a well-documented interplay between inflammation and angiogenesis [27]. Inflammation driven angiogenesis has been reported and for example MPO, secreted by neutrophils at inflamed sites, stimulated the angiogenic process in endothelial cells $[35,36]$. Thrombin also induced angiogenesis in endothelial cells [37]. On the other hand inflammatory stimuli can also impede angiogenic processes [38]. These reports combined with our observations that VEGF and FGF, two well characterized pro-angiogenic stimulators [39] induced APOL3 expression in HMEC-1, lead us to investigate the possible functional role of APOL3 in the angiogenic process.

Among the many coordinated processes involved in angiogenesis, cell proliferation, cell migration and tube formation are amenable to experimentation in culture through proliferation tests, scratch assays and tubulogenesis assays [40]. These assays were used to compare WT and APOL3 KO cells obtained using the CRISPR/Cas 9 technology. Our results suggest indeed APOL3 involvement in endothelial angiogenic activities.

In terms of wound healing, the capacity of APOL3 KO cells to fill a denudation zone in a confluent monolayer is partially disabled with respect to wild type cells, suggesting that migration is impaired. Our observation that APOL3 knock out didn't interfere with the normal proliferation rate rules argues against the trite possibility that the delay in closing the wound in APOL3 KO cells would only be due to an 
A

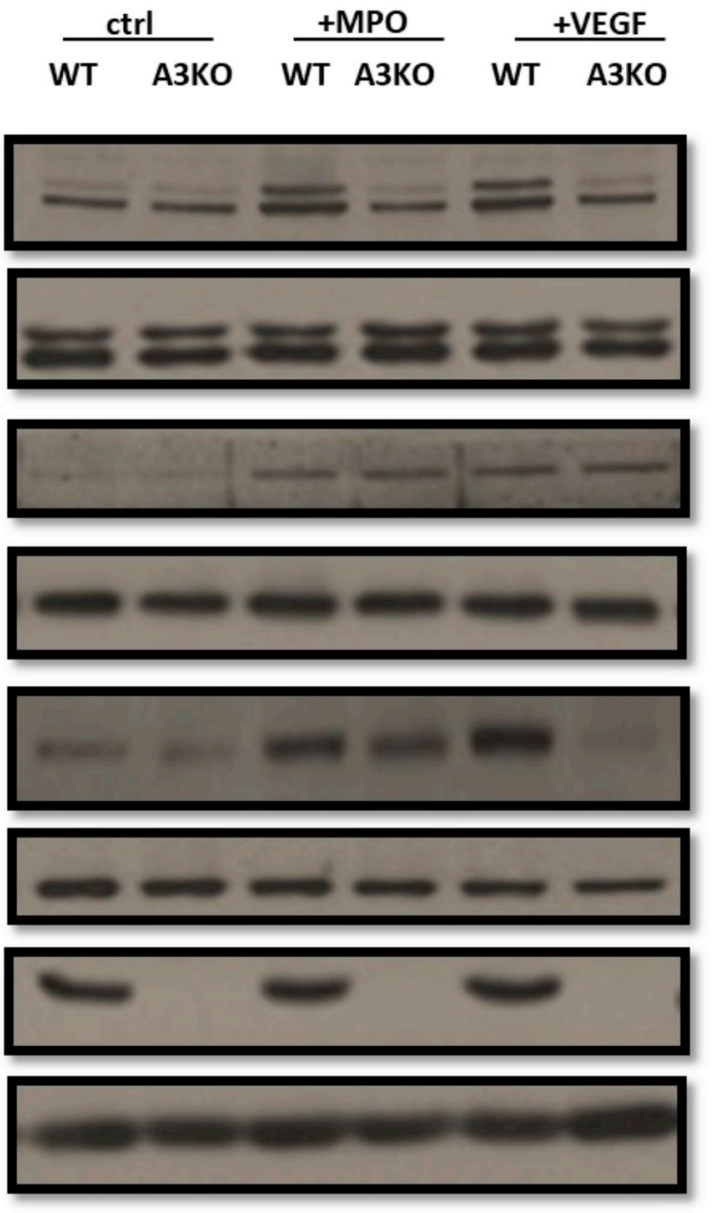

B

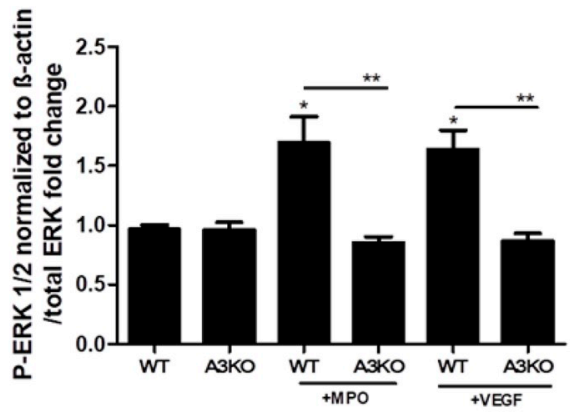

T-ERK1/2

P-Akt

C

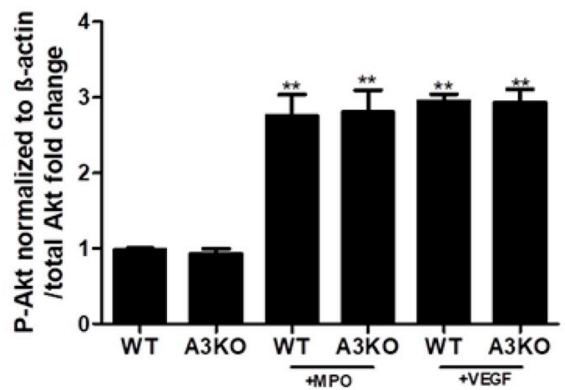

D

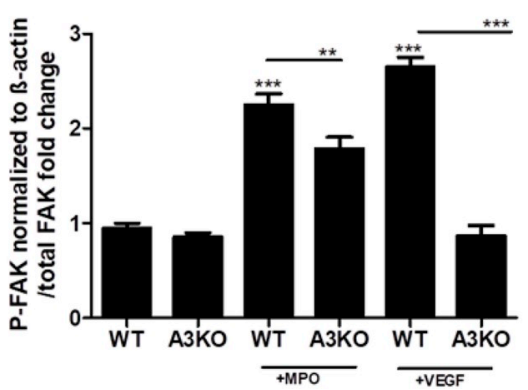

Fig. 7. Angiogenic signaling pathways in APOL3 KO cells.

(A) Wild type (WT) or APOL3 KO (A3KO) HMEC-1 cells were treated with MPO (200 ng/ml) or VEGF (100 ng/ml) for $1 \mathrm{~h}$. Western blot analysis of protein extracts was performed using the indicated antibodies. P: phosphorylated; T: total. Graphs (B, C, and D) show the quantification of phosphorylation levels of the indicated kinases normalized to $\beta$ actin and total kinase expression, and expressed as fold change over control. Results are shown as mean \pm SEM of three independent experiments. Statistics were performed using one-way ANOVA, followed by Bonferroni's Multiple Comparison Test. $\left({ }^{*} p<0.05\right.$, ${ }^{* *} p<0.01$, $\left.{ }^{* * *} p<0.001\right)$.

inhibition of proliferation. It suggested that there is indeed a bona fide involvement of APOL3 in endothelial cell migration. Finally, the ability of APOL3 KO cells to form tubules was only slightly (and statistically not significantly) reduced with respect to wild type cells. Given that APOL3 is induced by (inflammatory) stimuli that affect the angiogenic process, we repeated the same experiment in conditions of MPO, Thrombin and VEGF induced tubulogenesis. Our results showed that tubulogenesis is partially inhibited in APOL3 KO cells only under MPO, thrombin and VEGF treatment. Thus, APOL3 would participate in tubulogenesis only in inflammatory conditions when it is induced like after tissue injury. While considering pathological conditions such as inflammation, a documented inducer of angiogenesis is hypoxia $[41,42]$. We therefore tested if APOL3 would be involved in the hypoxic stress response. Expression of well known markers of hypoxic stress such as HIF1 $\alpha$, lactate dehydrogenase (LDH) or the glucose transporter GLUT1 [41,42] was not differentially affected (results not shown) between WT and APOL3 KO cells, suggesting that APOL3 is not directly involved (also see discussion below).

Another function of the endothelium is fluid partition between blood and tissues, related to its selective permeability. We show in this work that APOL3 KO correlates with an increase in endothelial permeability as assessed by fluorescent dye passage across a confluent endothelial monolayer. This effect is of the same extent than that of proinflammatory stimuli (as TNF- $\alpha$, known to induce endothelial hyperpermeability [26]) and suggests an involvement of APOL3 in endothelial permeability.

Our results also suggested that APOL3 is not uniformly involved to the same extent in different manifestations of the angiogenic phenotype. It is not unexpected that these manifestations involve a whole battery of actors and therefore APOL3 could cooperate with different molecules, acting in tubulogenesis (upon stimulation with MPO, Thrombin or VEGF) and in cell migration (without stimulation with MPO, Thrombin or VEGF). This suggestion is supported by our data regarding signal transduction pathways and gene expression. Indeed, in order to better understand the involvement of APOL3 in phenotypical changes we also investigated the angiogenic signaling pathways. We focused on extracellular signal-regulated kinases (ERK1/2) (necessary for tube formation), Focal Adhesion Kinase (FAK) (involved in the dynamic status of adhesion plaques mediating cell-matrix contact and cell movement) and Protein kinase B (Akt involved in cell proliferation) known to regulate cellular events required for new blood vessels formation [43-45]. Our results suggested that APOL3 is involved in some but not all angiogenic signal transduction pathways, as ERK1/2 and FAK, but not Akt, phosphorylation were inhibited in MPO and VEGF induced APOL3 KO cells. The fact that Akt phosphorylation was not affected also fitted with the lack of effect on cell growth. The 
A

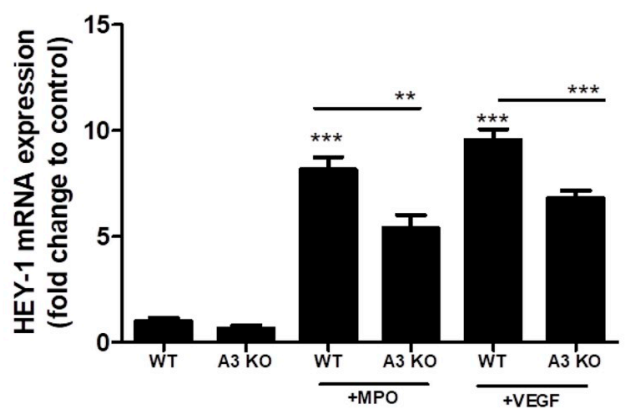

C

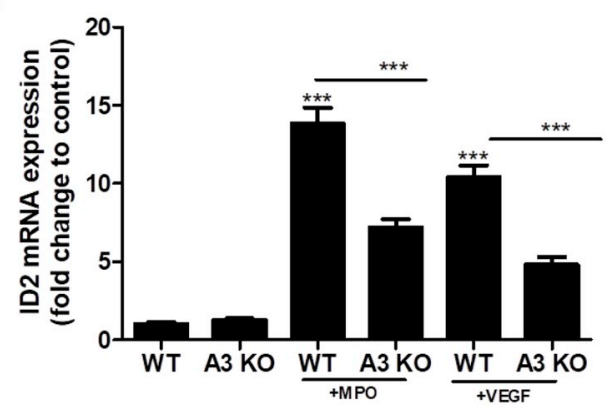

E

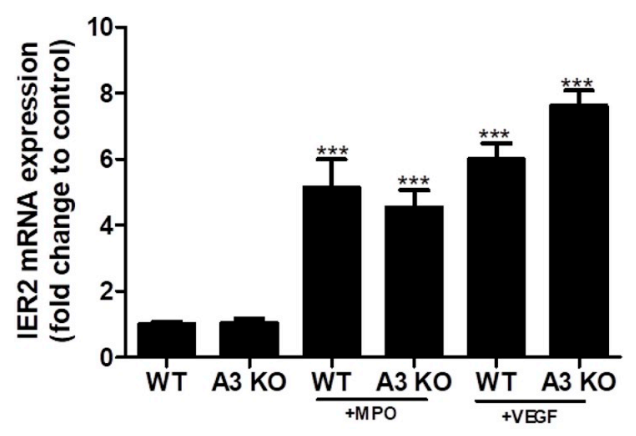

G

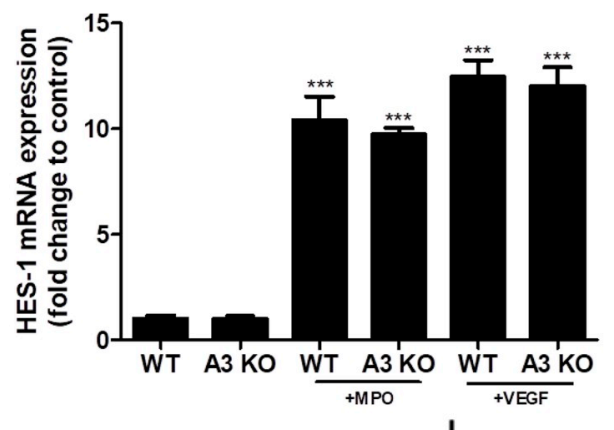

B
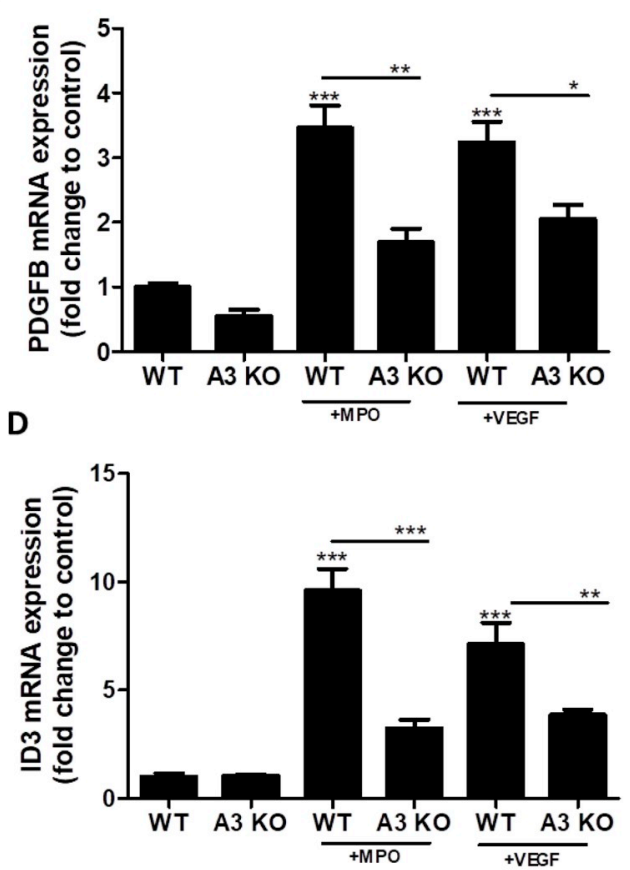

$\mathbf{F}$

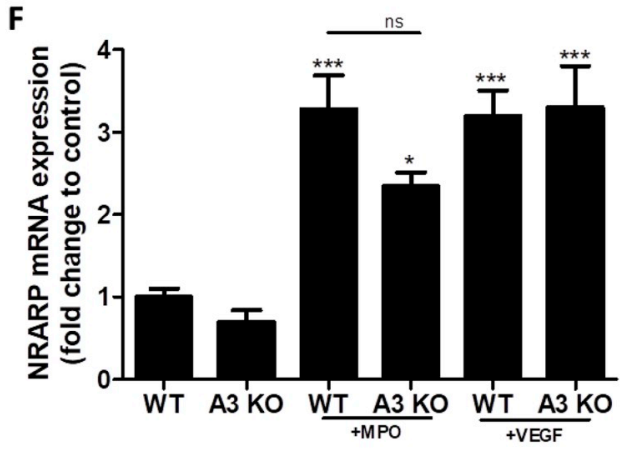

H

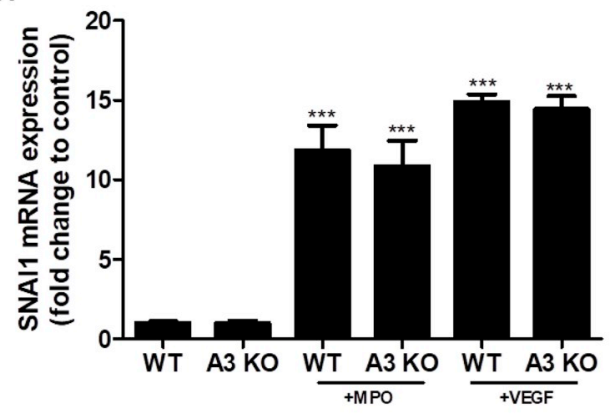

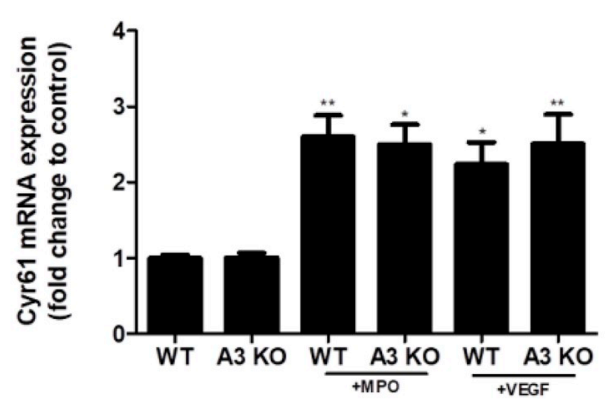

(caption on next page) 
Fig. 8. Pro-angiogenic gene expression in APOL3 KO cells.

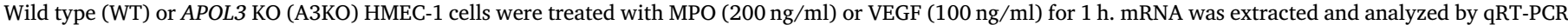

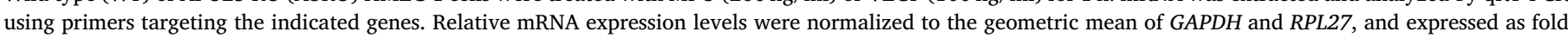

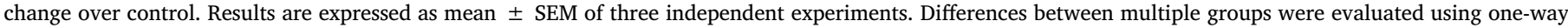
ANOVA followed by Bonferroni's Multiple Comparison Test. (ns: non-significant $p>0.05,{ }^{*} p<0.05,{ }^{* *} p<0.01, * * * p<0.001$ ).

involvement of APOL3 in only some angiogenic pathways is also supported by our observation that only four [HEY-1, PDGFB, ID2 and ID3] of the 9 angiogenic genes tested were dysregulated in APOL3 KO cells.

Our results also suggest that APOL3 is involved in endothelial permeability. There are several pathways controlling this property [46]. Our observation that APOL3 KO affects both ERK1/2 signaling and endothelial permeability is in agreement with the indication that the former is involved in the latter [47]. On the other hand our observations that APOL3 is not involved in hypoxic stress markers expression fits with the known direct (proximal) regulation of the hypoxic stress master regulator HIF1 $\alpha$ and its targets LDH and GLUT1 by $\mathrm{O}_{2}$ concentration. Nevertheless as hypoxia increases VEGF expression $[41,42]$ and VEGF increases APOL3 expression (this work), APOL3 could be involved in distal hypoxic signaling. This remains speculative as our work does not identify the molecular links between APOL3, endothelial permeability and angiogenesis.

Our work was also strictly limited to in vitro culture experiments. Therefore, immediate theoretical perspectives include the test of the APOL3 function in loss-of-function in vivo angiogenesis models. Unfortunately the lack of orthologues in other species (such as mice or zebrafish) precludes this possibility in the immediate future. Such investigations require the identification of the APOL3 paralogue inside the APOL gene family of these model organisms.

\subsection{Conclusions}

In summary, APOL3 is implicated in endothelial cell function. It participates in cell motility, inflammation-induced tubulogenesis, endothelial permeability, in angiogenic signal transduction pathways and angiogenic gene expression. This identifies APOL3 as an angiogenic molecule that could fine tune the action of major players such as VEGF in physiological angiogenesis or wound repair, vascular regeneration and re-endothelization after ischemic events and coronary stenting.

\section{Conflicts of interest}

The authors declared they do not have anything to disclose regarding conflict of interest with respect to this manuscript.

\section{Financial support}

AK is a recipient of AL-Azm et Saade association/Lebanese university scholarship. LVH is director of research at the Belgian National Fund for Scientific Research (FRS-FNRS). MFK was recipient of a Télévie fellowship. This research was financed by grants from the Fonds Jean Brachet, the Fonds de la chirurgie cardiaque, the Fonds de le Recherche Médicale en Hainaut (FRMH), a CDR from the FRS-FNRS, and a grant from the international Brachet stiftung to LVH.

\section{Author contributions}

$\mathrm{AK}, \mathrm{KZB}$, and LV designed the experiments; AK and PP performed the experiments; LDLs solutions were prepared by AR and VN. PP and MFK performed and controlled cell transfection. AK, PB, SU, PVA, KZB, and LV analyzed and interpreted the data; KZB and LV wrote the article and supervised the project; YM and BB provided technical support and discussed the data. All authors read and approved the final manuscript.

\section{Appendix A. Supplementary data}

Supplementary data to this article can be found online at https:// doi.org/10.1016/j.atherosclerosis.2018.10.023.

\section{References}

[1] P. Rajendran, T. Rengarajan, J. Thangavel, Y. Nishigaki, D. Sakthisekaran, G. Sethi, I. Nishigaki, The vascular endothelium and human diseases, Int. J. Biol. Sci. 9 (10) (2013) 1057-1069, https://doi.org/10.7150/ijbs.7502.

[2] P.N. Duchateau, C.R. Pullinger, R.E. Orellana, S.T. Kunitake, J. Naya-Vigne, P.M. O'Connor, M.J. Malloy, J.P. Kane, L. Apolipoprotein, A new human high density lipoprotein apolipoprotein expressed by the pancreas. Identification, cloning, characterization, and plasma distribution of apolipoprotein L, J. Biol. Chem. 272 (41) (1997) 25576-25582.

[3] P.N. Duchateau, I. Movsesyan, S. Yamashita, N. Sakai, K. Hirano, S.A. Schoenhaus, P.M. O'Connor-Kearns, S.J. Spencer, R.B. Jaffe, R.F. Redberg, B.Y. Ishida, Y. Matsuzawa, J.P. Kane, M.J. Malloy, Plasma apolipoprotein L concentrations correlate with plasma triglycerides and cholesterol levels in normolipidemic, hyperlipidemic, and diabetic subjects, J. Lipid Res. 41 (8) (2000) 1231-1236.

[4] T.S. Albert, P.N. Duchateau, S.S. Deeb, C.R. Pullinger, M.H. Cho, D.C. Heilbron, M.J. Malloy, J.P. Kane, B.G. Brown, Apolipoprotein L-I is positively associated with hyperglycemia and plasma triglycerides in CAD patients with low HDL, J. Lipid Res. 46 (3) (2005) 469-474, https://doi.org/10.1194/jlr.M400304-JLR200.

[5] L. Vanhamme, F. Paturiaux-Hanocq, P. Poelvoorde, D.P. Nolan, L. Lins, J. Van Den Abbeele, A. Pays, P. Tebabi, H. Van Xong, A. Jacquet, N. Moguilevsky, M. Dieu, J.P. Kane, P. De Baetselier, R. Brasseur, E. Pays, Apolipoprotein L-I is the trypanosome lytic factor of human serum, Nature 422 (6927) (2003) 83-87, https://doi. org $/ 10.1038 /$ nature01461.

[6] E.E. Smith, H.S. Malik, The apolipoprotein L family of programmed cell death and immunity genes rapidly evolved in primates at discrete sites of host-pathogen interactions, Genome Res. 19 (5) (2009) 850-858, https://doi.org/10.1101/gr. 085647.108.

[7] P. Beckerman, J. Bi-Karchin, A.S. Park, C. Qiu, P.D. Dummer, I. Soomro, C.M. Boustany-Kari, S.S. Pullen, J.H. Miner, C.A. Hu, T. Rohacs, K. Inoue, S. Ishibe, M.A. Saleem, M.B. Palmer, A.M. Cuervo, J.B. Kopp, Susztak, Transgenic expression of human APOL1 risk variants in podocytes induces kidney disease in mice, Nat. Med. 23 (4) (2017) 429-438, https://doi.org/10.1038/nm.4287.

[8] D. Pérez-Morga, B. Vanhollebeke, F. Paturiaux-Hanocq, D.P. Nolan, L. Lins, F. Homblé, L. Vanhamme, P. Tebabi, A. Pays, P. Poelvoorde, A. Jacquet, R. Brasseur, E. Pays, Apolipoprotein L-I promotes trypanosome lysis by forming pores in lysosomal membranes, Science 309 (5733) (2005) 469-472, https://doi. org $/ 10.1126 /$ science. 1114566 .

[9] G. Wan, S. Zhaorigetu, Z. Liu, R. Kaini, Z. Jiang, C.A. Hu, Apolipoprotein L1, a novel Bcl-2 homology domain 3-only lipid-binding protein, induces autophagic cell death, J. Biol. Chem. 283 (31) (2008) 21540-21549, https://doi.org/10.1074/jbc. M800214200.

[10] Z. Liu, H. Lu, Z. Jiang, A. Pastuszyn, C.A. Hu, Apolipoprotein L6, a novel proapoptotic Bcl-2 homology 3-only protein, induces mitochondria-mediated apoptosis in cancer cells, Mol. Cancer Res. MCR 3 (1) (2005) 21-31.

[11] W. Liao, F.Y. Goh, R.J. Betts, D.M. Kemeny, J. Tam, B.H. Bay, W.S. Wong, A novel anti-apoptotic role for apolipoprotein L2 in IFN-gamma induced cytotoxicity in human bronchial epithelial cells, J. Cell. Physiol. 226 (2) (2011) 397-406, https:// doi.org/10.1002/jcp.22345.

[12] H. Monajemi, R.D. Fontijn, H. Pannekoek, A.J. Horrevoets, The apolipoprotein L gene cluster has emerged recently in evolution and is expressed in human vascular tissue, Genomics 79 (4) (2002) 539-546, https://doi.org/10.1006/geno.2002. 6729.

[13] T.R. Sana, M.J. Janatpour, M. Sathe, L.M. McEvoy, T.K. McClanahan, Microarray analysis of primary endothelial cells challenged with different inflammatory and immune cytokines, Cytokine 29 (6) (2005) 256-269, https://doi.org/10.1016/j. cyto.2004.11.003.

[14] S. Uzureau, C. Coquerelle, C. Vermeiren, Van Acker A. Uzureau, L. Pilotte, D. Monteyne, V. Acolty, B. Vanhollebeke, B. Van den Eynde, D. Pérez-Morga, M. Moser, E. Pays, Apolipoproteins L control cell death triggered by TLR3/TRIF signaling in dendritic cells, Eur. J. Immunol. 46 (8) (2016) 1854-1866, https://doi org/10.1002/eji.201546252.

[15] N. Moguilevsky, L. Garcia-quintana, A. Jacquet, C. Tournay, L. Fabry, L. Pierard, A. Bollen, Structural and biological properties of human recombinant myeloperoxidase produced by Chinese hamster ovary cell lines, Eur. J. Biochem. 197 (1991) 605-614, https://doi.org/10.1111/j.1432-1033.1991.tb15950.x.

[16] N.N. Mehta, H.L. Teague, W.R. Swindell, Y. Baumer, N.L. Ward, X. Xing, B. Baugous, A. Johnston, A.A. Joshi, J. Silverman, D.H. Barnes, L. Wolterink, R.P. Nair, P.E. Stuart, M. Playford, J.J. Voorhees, M.K. Sarkar, J.T. Elder, K. Gallagher, S.K. Ganesh, J.E. Gudjonsson, IFN- $\gamma$ and TNF- $\alpha$ synergism may 
provide a link between psoriasis and inflammatory atherogenesis, Sci. Rep. 7 (1) (2017) 13831, https://doi.org/10.1038/s41598-017-14365-1.

[17] E. Dupuy, A. Habib, M. Lebret, R. Yang, S. Levy-Toledano, G. Tobelem, Thrombin induces angiogenesis and vascular endothelial growth factor expression in human endothelial cells: possible relevance to HIF-1alpha, J. Thromb. Haemostasis 1 (5) (2003) 1096-1102, https://doi.org/10.1046/j.1538-7836.2003.00208.x.

[18] A. Aminian, K.Z. Boudjeltia, S. Babar, P. Van Antwerpen, P. Lefebvre, V. Crasset, A. Leone, J. Ducobu, A. Friart, M. Vanhaeverbeek, Coronary stenting is associated with an acute increase in plasma myeloperoxidase in stable angina patients but not in patients with acute myocardial infarction, Eur. J. Intern. Med. 20 (5) (2009) 527 DOI: 32. 10.1016/j.ejim.2009.05.008.

[19] S. Baldus, C. Heeschen, T. Meinertz, A.M. Zeiher, J.P. Eiserich, T. Münzel, M.L. Simoons, C.W. Hamm, Myeloperoxidase serum levels predict risk in patients with acute coronary syndromes, Circulation 108 (12) (2003) 1440-1445, https:// doi.org/10.1161/01.CIR.0000090690.67322.51.

[20] C. Delporte, P. Van Antwerpen, L. Vanhamme, T. Roumeguère, K. Zouaoui Boudjeltia, Low-density lipoprotein modified by myeloperoxidase in inflammatory pathways and clinical studies, Mediat. Inflamm. 2013 (2013) 971579, https://doi. org/10.1155/2013/971579.

[21] E. Zudaire, L. Gambardella, C. Kurcz, S. Vermeren, A computational tool for quantitative analysis of vascular networks, PloS One 6 (11) (2011) e27385, , https://doi.org/10.1371/journal.pone.0027385.

[22] J.S. Esser, S. Rahner, M. Deckler, C. Bode, C. Patterson, M. Moser, Fibroblast growth factor signaling pathway in endothelial cells is activated by BMPER to promote angiogenesis, Arterioscler. Thromb. Vasc. Biol. 35 (2) (2015) 358-367, https://doi. org/10.1161/ATVBAHA.114.304345.

[23] V. Vouret-Craviari, P. Boquet, J. Pouysségur, E. Van Obberghen-Schilling, Regulation of the actin cytoskeleton by thrombin in human endothelial cells: role of Rho proteins in endothelial barrier function, Mol. Biol. Cell 9 (9) (1998) 2639-2653.

[24] D.R. Senger, S.J. Galli, A.M. Dvorak, C.A. Perruzzi, V.S. Harvey, H.F. Dvorak, Tumor cells secrete a vascular permeability factor that promotes accumulation of ascites fluid, Science 219 (1983) 983-985.

[25] W.G. Roberts, G.E. Palade, Increased microvascular permeability and endothelial fenestration induced by vascular endothelial growth factor, J. Cell Sci. 108 (6) (1995) 2369-2379.

[26] A. Burke-Gaffney, A.K. Keenan, Modulation of human endothelial cell permeability by combinations of the cytokines interleukin- 1 alpha/beta, tumor necrosis factoralpha and interferon-gamma, Immunopharmacology 25 (1) (1993) 1-9.

[27] M.R. De Vries, P.H. Quax, Plaque angiogenesis and its relation to inflammation and atherosclerotic plaque destabilization, Curr. Opin. Lipidol. 27 (5) (2016) 499-506, https://doi.org/10.1097/MOL.0000000000000339.

[28] A. Tedgui, Z. Mallat, Cytokines in atherosclerosis: pathogenic and regulatory pathways, Physiol. Rev. 86 (2) (2006) 515-581, https://doi.org/10.1152/physrev. 00024.2005.

[29] L.J. Hazell, G. Baernthaler, R. Stocker, Correlation between intima-to-media ratio, apolipoprotein B-100, myeloperoxidase, and hypochlorite-oxidized proteins in human atherosclerosis, Free Radic. Biol. Med. 31 (10) (2001) 1254-1262.

[30] B. Valente-Acosta, M.A. Baños-González, M.A. Peña-Duque, M.A. Martínez-Ríos, L. Quintanar-Trejo, G. Aptilon-Duque, M. Flores-García, D. Cruz-Robles, G. CardosoSaldaña, A. de la Peña-Díaz, Association between stable coronary artery disease and in vivo thrombin generation, Cardiol. Res. Pract. (2016), https://doi.org/10.1155/ 2016/5149825 5 pages.

[31] S. Zhaorigetu, Z. Yang, I. Toma, T.A. McCaffrey, C.-A.A. Hu, Apolipoprotein L6, induced in atherosclerotic lesions, promotes apoptosis and blocks beclin 1-dependent autophagy in atherosclerotic cells, J. Biol. Chem. 286 (31) (2011) 27389-27398, https://doi.org/10.1074/jbc.M110.210245.

[32] A. Horrevoets, R. Fontijn, A.J. Van Zonneveld, C.J. de Vries, J.W. Cate, H. Pannekoek, Vascular endothelial genes that are responsive to tumor necrosis factor- $\alpha$ in vitro are expressed in atherosclerotic lesions, including inhibitor of apoptosis protein-1, stannin, and two novel genes, Blood 93 (10) (1999) 3418-3431.

[33] H.R. Park, H. Yang, G.D. Kim, G.W. Son, Y.S. Park, Microarray analysis of gene expression in 3-methylcholanthrene-treated human endothelial cells, Mol. Cell Toxicol. 10 (1) (2014) 19-27, https://doi.org/10.1007/s13273-014-0003-1.

[34] A. Matsuda, Y. Suzuki, G. Honda, S. Muramatsu, O. Matsuzaki, Y. Nagano, T. Doi, K. Shimotohno, T. Harada, E. Nishida, H. Hayashi, S. Sugano, Large-scale identification and characterization of human genes that activate NF-KB and MAPK signaling pathways, Oncogene 22 (21) (2003) 3307-3318, https://doi.org/10.1038/ sj.onc.1206406.

[35] V. Panagopoulos, I. Zinonos, D.A. Leach, S.J. Hay, V. Liapis, A. Zysk, W.V. Ingman, M.O. DeNichilo, A. Evdokiou, Uncovering a new role for peroxidase enzymes as drivers of angiogenesis, Int. J. Biochem. Cell Biol. 68 (2015) 128-138, https://doi. org/10.1016/j.biocel.2015.09.006.

[36] A. Khalil, H. Medfai, P. Poelvoorde, M. Fayyad-Kazan, C. Delporte, P. Van Antwerpen, Y. El-Makhour, P. Biston, P. Delrée, B. Badran, L. Vanhamme, K.Z. Boudjeltia, Myeloperoxidase promotes tube formation, triggers ERK1/2 and Akt pathways and is expressed endogenously in endothelial cells, Arch. Biochem. Biophys. 654 (2018) 55-69, https://doi.org/10.1016/j.abb.2018.07.011.

[37] N.E. Tsopanoglou, P. Andriopoulou, M.E. Maragoudakis, On the mechanism of thrombin-induced angiogenesis: involvement of avß3-integrin, Am. J. Physiol. Cell Physiol. 283 (5) (2002) 1501-1510.

[38] J. Daher, M. Martin, A. Rousseau, V. Nuyens, H. Fayyad-Kazan, P. Van Antwerpen, G. Courbebaisse, P. Martiat, B. Badran, F. Dequiedt, K. Zouaoui Boudjeltia, L. Vanhamme, Myeloperoxidase oxidized LDL interferes with endothelial cell motility through miR-22 and heme oxygenase 1 induction: possible involvement in $\mathrm{Re}-$ endothelialization of vascular injuries, Mediat. Inflamm. 2014 (2014) 134635, https://doi.org/10.1155/2014/134635.

[39] M.J. Cross, L. Claesson-Welsh, FGF and VEGF function in angiogenesis: signalling pathways, biological responses and therapeutic inhibition, Trends Pharmacol. Sci. 22 (4) (2001) 201-207.

[40] B. Vailhe, D. Vittet, J.J. Feige, In vitro models of vasculogenesis and angiogenesis, Lab. Invest. 81 (2001) 439-452.

[41] B.W. Wong, E. Marsch, L. Treps, M. Baes, P. Carmeliet, Endothelial cell metabolism in health and disease: impact of hypoxia, EMBO J. 36 (15) (2017) 2187-2203, https://doi.org/10.15252/embj.201696150.

[42] A.J. Majmundar, W.J. Wong, M.C. Simon, Hypoxia-inducible factors and the response to hypoxic stress, Mol. Cell. 40 (2) (2010) 294-309, https://doi.org/10. 1016/j.molcel.2010.09.022.

[43] R. Srinivasan, T. Zabuawala, H. Huang, J. Zhang, P. Gulati, S. Fernandez, J. Karlo, G.E. Landreth, G. Leone, M.C. Ostrowski, Erk1 and Erk2 regulate endothelial cell proliferation and migration during mouse embryonic angiogenesis, PloS One 4 (12) (2009) e8283, , https://doi.org/10.1371/journal.pone.0008283.

[44] X. Zhao, J.L. Guan, Focal adhesion kinase and its signaling pathways in cell migration and angiogenesis, Adv. Drug Deliv. Rev. 63 (8) (2011) 610-615, https:// doi.org/10.1016/j.addr.2010.11.001.

[45] J. Karar, A. Maity, PI3K/AKT/mTOR pathway in angiogenesis, Front. Mol. Neurosci. 4 (2011) 51, https://doi.org/10.3389/fnmol.2011.00051.

[46] Y. Komarova, A.B. Malik, Regulation of endothelial permeability via paracellular and transcellular transport pathways, Annu. Rev. Physiol. 72 (2010) 463-493, https://doi.org/10.1146/annurev-physiol-021909-135833.

[47] C. Chang, H. Liu, C. Wei, L. Chang, J. Liang, H. Bei, H. Li, S. Liu, Y. Wu, Tongxinluo regulates expression of tight junction proteins and alleviates endothelial cell monolayer hyperpermeability via ERK-1/2 signaling pathway in oxidized lowdensity lipoprotein-induced human umbilical vein endothelial cells, Evid. Based Complement. Alternat. Med. 2017 (2017) 4198486, https://doi.org/10.1155/ $2017 / 4198486$ 